\title{
Different solutions lead to similar life history traits across the great divides of the amniote tree of life
}

Shai Meiri ${ }^{1,2^{*}} \mathbb{0}$, Gopal Murali ${ }^{3}$, Anna Zimin ${ }^{1}$, Lior Shak ${ }^{1}$, Yuval Itescu ${ }^{4,5}$, Gabriel Caetano ${ }^{3}$ and Uri Roll ${ }^{3}$

\begin{abstract}
Amniote vertebrates share a suite of extra-embryonic membranes that distinguish them from anamniotes. Other than that, however, their reproductive characteristics could not be more different. They differ in basic ectothermic vs endothermic physiology, in that two clades evolved powered flight, and one clade evolved a protective shell. In terms of reproductive strategies, some produce eggs and others give birth to live young, at various degrees of development. Crucially, endotherms provide lengthy parental care, including thermal and food provisioning —whereas ectotherms seldom do. These differences could be expected to manifest themselves in major differences between clades in quantitative reproductive traits. We review the reproductive characteristics, and the distributions of brood sizes, breeding frequencies, offspring sizes and their derivatives (yearly fecundity and biomass production rates) of the four major amniote clades (mammals, birds, turtles and squamates), and several major subclades (birds: Palaeognathae, Galloanserae, Neoaves; mammals: Metatheria and Eutheria). While there are differences between these clades in some of these traits, they generally show similar ranges, distribution shapes and central tendencies across birds, placental mammals and squamates. Marsupials and turtles, however, differ in having smaller offspring, a strategy which subsequently influences other traits.
\end{abstract}

Keywords: Amniotes, Aves, Breeding frequency, Cleidoic egg, Clutch size, Ectothermy, Endothermy, Litter size, Mammalia, Metabolic rates, Offspring size, Parental care, Reproductive investment, Reptilia, Squamata

\section{Introduction}

The emergence of amniotic vertebrates was a remarkable event in the evolutionary history of life on Earth. Amniotes developed a triumvirate of extraembryonic membranes: the amnion, the allantois, and the chorion. This had enabled them to successfully colonize the terrestrial environment and eliminate the need to reproduce in water [1]. Arguably these membranes allowed them to evolve a host of morphologies and ecologies and become the dominant form of life on Earth (at least in term of body size, and its associated influence on food webs, vegetation structure etc.).

\footnotetext{
*Correspondence: uncshai@tauex.tau.ac.il

${ }^{1}$ School of Zoology, Tel Aviv University, 6997801 Tel Aviv, Israel

Full list of author information is available at the end of the article
}

The evolution of the amniotic developmental strategy was associated with a general enlargement of the embryos, and a general reduction in their numbers, compared to anamniote vertebrates. Some fishes can lay millions of tiny eggs (e.g., the Atlantic cod, Gadus morhua [2, 3]; Sebastes sp. rockfishes [4]; the common ling, Molva molva [5]; the ocean sunfish, Mola mola [6]). Some anurans (mostly bufonids) can lay 35,000 or more eggs in a clutch (e.g., the cane toad, Rhinella marina [7], the green toad, Bufotes viridis, [8], the Great-Plains toad, Anaxyrus cognatus, can lay over 45,000 eggs, [9] and Rhinella jimi may lay over 50,000 eggs, [10]). Despite being, on average, much larger bodied than amphibians, the maximum clutch size of amniotes is over two orders of magnitude smaller (maximum 242 eggs in the hawksbill sea turtle, Eretmochelys imbricata [11]). It is logical to assume that 
the complexity and energetic cost of the amniote embryonic development sets a much higher bar for minimum offspring size [12] than the relatively simple embryogenesis of anamniotes.

While sharing the basic set of extraembryonic membranes, major amniote clades have diverged from one another, over hundreds of millions of years, adopting widely disparate physiologies, morphologies [1] and reproductive strategies. Active flight constrain the output of a single reproductive event (so as not to impose a burden of the mother carrying eggs or, in bats, neonates; e.g., [13]). It may explain why birds produce one egg per day whereas reptiles lay the entire clutch in minutes or hours, and the degree of parental care in birds was found to be negatively related to productivity rates [14]. Flight evolved independently in three amniote lineages (two of them extant). Endothermy evolved twice in extant amniotes, in the lineages leading to crown group mammals and birds. Endotherms lead much more energetically expensive lives than ectotherms. At rest, endotherms spend ten times the energy than similar-sized ectotherms do [15]. This means that endotherms spend more of their energy on maintenance, whereas ectotherms spend relatively more of their available energy on reproduction (e.g., [16, 17], see also Bonnet et al. [18]). Endotherms therefore spend much more energy to produce a similar biomass of offspring [19]. Some have argued that this allows ectotherms to out-do endotherms in terms of both numbers of offspring and biomass production rates $[20$, 21].

\section{Viviparity and parental care}

Viviparity evolved once in therians-and dozens of times in squamates [22], but crucially never (as far as we know) in extant archelosaurs (turtles, birds, and crocodiles). Parental care (here: only in the form of post-partum/ post-hatching care) also probably evolved once in birds (or in the lineage leading to birds; [23]) and once in mammals [24]. It evolved several times in squamates [25-27], but most species of squamates do not care for their young [28-31]. Crocodiles tend their eggs and young for a short period [26, 28, 30], while turtles do not. Yet, it was the endotherm revolution that became associated with ubiquitous, and often lengthy, parental care [25, 31, 32] which always extends to the post-hatching/birth period. It is associated with extensive parental provisioning of both food and warmth. The reptilian version of parental care, on the other hand, is more rudimentary. It is often limited to the eggs, does not extend to provisioning of the young, and is usually a much simpler, shorter affair where mothers at best tolerate their offspring, providing passive defense [18,26,30], though active defense can occur, e.g., [33]. In contrast, actively providing food, thermal shelters, and teaching skills are all hallmarks of endotherm parental care. Endotherms nearly always invest in their offspring for a lengthy period after offspring are born or hatch, which necessitates considerable parental energy investment, whereas reptilian offspring are independent at birth, almost never requiring any further parental investment $[25,34]$.

The evolution of both viviparity and parental care is energetically costly $[35,36]$ and forces the mother to forgo future opportunities for reproduction. These traits are therefore often thought to promote shifts towards 'slower' life histories and towards the K strategy along the r-K continuum (e.g., [37-39]).

In fishes, amphibians and squamates (i.e. vertebrates in which there is variation with regards to both reproductive mode and parental care- unlike birds and therian mammals) live bearers, and species practicing parental care, have smaller broods ([5, 40-43], but see [44, 45] for squamates and [46] for elasmobranchs). Live bearers and species practicing parental care also have larger offspring or eggs than similar-sized oviparous and non-caring species $([6,41-43,46-53]$, but see [54]). Reproductive frequency is lower in viviparous taxa and in those practicing forms of parental care [28, 40, 44, 45, 55-58]. Finally, viviparous taxa mature later $([44,45,59,60]$ but see [61]), and live longer ([59] but see [62]). These associations have independently evolved in a variety of anamniote vertebrate clades [63] including elasmobranchs $[46,53]$, teleosts (e.g., [48, 53, 59]), and amphibians (e.g., [43]), as well as in a suit of invertebrate taxa [63].

Within amniote classes, major clades often fundamentally differ from one another in several key life-history characteristics. In birds, perhaps the most uniform of the three classes (in terms of gross morphology and life history strategy), members of the Palaeognathae and Galloanserae, tend to have highly precocial young, whereas altricial young dominate in the Neoaves [64]. The reptilian clades Testudines and Crocodilia are phylogenetically further apart from other reptiles (Lepidosauria) than they are from Aves (birds) (e.g., [65-67]). The highly restrictive morphology of the turtle shell may restrict egg size [68]. Furthermore, while parental care is ubiquitous in crocodiles, it is totally absent in turtles, and rare in squamates $([28,30]$ and see above). Thus, it is reasonable to expect divergent life history evolution across clades. Within squamates the repeated evolution of viviparity was long hypothesized to strongly affect a plethora of life history traits, generally creating a shift toward larger, fewer offspring per reproductive event, as well as less frequent reproduction (because embryos are carried in the uterus until parturition [58, 63, 69-71]; cf. [72]). While some have argued viviparous squamates have larger offspring than oviparous ones [43, 63, 70,71], Meiri et al. 
[72] have shown this is not the case. In mammals, oviparity is restricted to monotremes, but placentals and marsupials (all viviparous) take fundamentally different approaches to embryonic development [1] and life history [73]. Marsupials are born at a very early ontogenetic stage, and after a much shorter gestation, than placentals $[73,74]$. After birth marsupials spend an extended period in the pouch, weaning at an older age than similar-sized placentals [75].

\section{Life-history allometry}

A factor that is well known to govern the evolution of life histories in all animal taxa is body size [76-78]. In some lineages of anamniote vertebrates offspring size scales positively with adult size (e.g., $[6,48,52,53,79]$; see also Figure 4 in [80]). In other anamniote lineages, however, mothers lay very small eggs, regardless of their own size, resulting in a flat body size-egg size relationship (e.g., teleosts: [6, 80, 81] cf. [82] and Amphibians: [83, 84]). In amniotes, a positive linear relationship between offspring (or egg) size and adult size across species is ubiquitous (e.g., [57, 75, 85-89] and see below).

The allometry of clutch and litter sizes, however, differs greatly between the amniote classes (e.g., [90] and see below). Clutch sizes generally increase with body size across the animal kingdom, both in invertebrates (e.g., [86, 91-93]) and in anamniote vertebrates (fishes: [53, 80, 82, 94]; amphibians: [6, 40, 52, 79, 84]). Reptile clutch sizes similarly increase with maternal body size $[44,45$, 57, 87, 95-97]. Several species-rich lizard lineages (e.g., Gekkota, Gymnophthalmidae, Dactyloidae), however, evolved fixed clutches of one or two eggs, irrespective of body size $[12,98,99]$.

In contrast, large sized mammals usually have small litters (most often of a single neonate) while smaller mammals have larger litters ([100-102]; cf. [103]). One major mammalian lineage, however, the Chiroptera (bats), is characterized by invariantly small litters of one or, rarely, two neonates (very rarely more [104]). Likewise the Primates also have litters of only one or two young (e.g., $[105,106])$, but even in primates larger species tend to have a litter size of one, and smaller ones bear two offspring [106].

In birds, the relationship between clutch size and body size is usually thought to be negative, similar to the mammalian pattern, but the slope of this relationship is usually very shallow ([77, 101, 107, 108]; cf. [109]). Unlike mammals, however, the largest birds (i.e. the ratites), do not have small clutches (the smallest of them, the Kiwis, Apteryx spp. have clutch sizes of one [110] whereas rheas and ostriches have larger clutches). Furthermore, almost all the (invariably large bodied) members of the Galloanserae have large clutches (data from [107]). Clutch size/body size relationships may also differ between altricial and precocial birds [111], cf. [108]. These disparate relationships may result in differences in the allometry fecundity rates (young hatching/born per year) differing across amniote taxa.

Reproduction frequency decreases with body size in all major amniote taxa [57, 87, 101, 112-117]. On the other hand, rates of biomass production [57, 102, 116, 118], age at maturity $[59,61,76,87,114,119]$, and longevity [62, 120-123], all increase with body size.

While we envision class-level and other such higherorder differences between the life history characteristics of major amniote taxa, all the quantitative measures we examine also exhibit considerable intra-clade variability. Much of this variation has been attributed to the major disparity in body size within amniote classes ranging across five orders of magnitude in extant birds, seven orders of magnitude in extant reptiles (nine if the extinct mosasaurs are considered) and eight orders of magnitude in mammals (see below).

In reptiles parental care is too rare, and potentially too rudimentary, to explain much of the intra-class variance. Viviparity, however, evolved many times in squamate reptiles [22], and furthermore manifests great variability in the degree of fetal provisioning and placentationfrom ovoviviparity to placental mammal-like nutrient exchange [124]. This allows meaningful testing of the effects of viviparity in a phylogenetic context $[45,57,97$, 118, 125-129] which makes the Squamata a fantastic model in which to directly test for the evolutionary implications the evolution of viviparity may have had for life history evolution.

Our working hypothesis is that the major differences in phylogeny, reproductive mode, parental provisioning and thermal biology, will lead to measurable quantitative differences among several reproductive indices. Specifically we hypothesize that: (1) Endothermy (coupled with parental provisioning of birds and mammals) will result in larger offspring than those of similar-sized ectotherms. Thus mammals and birds will have larger neonates and hatchlings than reptiles with similar-sized mothers (cf. [54]); (2) Endotherms will have fewer offspring per litter/clutch than ectotherms, and viviparous squamates will have smaller broods than oviparous ones, because of their higher investment in parental care, and due to constraints imposed by maternal body volume and resource availability necessitate a tradeoff; (3) Squamate viviparity will be associated with less frequent reproduction because of the need to carry embryos to full term in the reproductive tract. Oviparous species on the other hand can lay eggs when embryos are at an early developmental stage and are immediately free to reproduce again. Furthermore, viviparous squamates predominate 
in high-latitude, highly seasonal, regions [130]—where seasons are short and hence also likely to reproduce less frequently. Because of their lengthy parental care, we predict that mammals and birds reproduce less often than oviparous reptiles; (4) Endothermy and viviparity will therefore be associated with lower rates of biomass production. Alternatively, endothermy accelerates metabolic rate and hence embryonic development may be faster, resulting in accelerated production rates. We test these hypotheses by comparing the life history characters of mammals, reptiles, and birds - with emphasis on the overall variation in these traits rather than on strictly quantitative measures of central tendency.

\section{Methods}

Data

We obtained data on vertebrate life history and reproduction characteristics from the literature. Data on mammal life histories are from the PanTHERIA dataset [104]. Litter sizes smaller than one in PanTHERIA were changed to one. Data on birds are from Jetz et al. (clutch sizes; [107]), Sibly et al. (annual mass production; [117]), and Myrvhold et al. (all other data; [131]). Data for turtles are from the primary literature. Data for squamates are from Feldman et al. (snake reproductive mode; [130]), Feldman (snake life history; [132]), Meiri et al. (lizard clutch sizes; [97]), and Meiri (all other data for lizards, [54, 133]), supplemented with data from the primary literature for snakes. Data for offspring sizes are from Meiri [54], with minor updates for reptiles.

We collected the following types of data, that are comparable across all taxa: (1) Mean body mass of adult females or (when unavailable) of unsexed adults (in g). (2) Mean body mass of hatchlings or neonates (in g). (3) Clutch or litter size. (4) The number of yearly clutches or litters (henceforth "broods"). Also, the following composite measures were considered: (5) Relative brood mass (i.e. attribute \#3 times attribute \#4 divided by attribute \#2). (6) The number of young produced per year (attribute \#4 times attribute $\# 5$, individuals $\times$ year $^{-1}$ ). We omitted incorrect values of $>100$ offspring a year for two cuckoo and six megapode species [131]. These are more than twice the next value, and we suspect confound clutch size and clutch frequency (e.g., incorrect value of 12 clutches of 9.2 eggs for Cuculus canorus cf. [134-136]; erroneous 21 clutches of 14.8 eggs for Alectura lathami which actually lay one egg at a time: [137], San Diego Zoo 2018). (7) The biomass produced by a female per year (attribute $\# 3 \times$ attribute $\# 4 \times$ attribute $\# 5, \mathrm{~g} \times$ year $^{-1}$ ).

Body size data are reported for endotherms as body masses (e.g., [114, 117]). For reptiles, however, mass data are rarely reported [138, 139]. Therefore-and to make sure data are comparable between reptiles and endotherms - we converted lengths to masses using the allometric equations published by Feldman et al. [140]. We note that such conversion is crucial not only for interclass comparisons but also between squamate clades that differ much in their shape. For example, at the collections of the Steinhardt Museum of Natural History, Tel Aviv University, a $200 \mathrm{~mm}$ long snake (Letheobia simoni, snout-vent length $=\mathrm{SVL}$, specimen \#6397) weighs $0.7 \mathrm{~g}$ whereas a dragon lizard, Pogona barbata (specimen \#14010) of exactly the same SVL (200 mm) weighs over 400 times as much $(292 \mathrm{~g})$. A somewhat shorter turtle (Mauremys rivulata, specimen \#9652, $150 \mathrm{~mm}$ carapace length) is even heavier (372 g). There are 12,659 specimens with both mass and either SVL or carapace length data in this collection (including six amphisbaenian, 34 crocodile, 22 turtle, 5110 snake, and 7478 lizard specimens). The OLS slopes of $\log _{10}$ mass on $\log _{10}$ length regression are similar across taxa (2.79 for turtle carapace length, and for SVLs: 2.80 for crocodiles, 2.87 for lizards and 2.77 for snakes, $\mathrm{R}^{2}$ values: $0.82,0.91,0.91$ and 0.86 , respectively). The intercepts, however, are vastly different $(-3.47$ for turtles, -4.22 for crocodiles, -4.41 for lizards and -5.72 for snakes). Thus at $150 \mathrm{~mm} \mathrm{SVL}$ these equations predict a turtle will weigh $403 \mathrm{~g}$, while a (very small) crocodile will weigh $75 \mathrm{~g}$, a lizard $69 \mathrm{~g}$ and a snake only $2 \mathrm{~g}$ (Fig. 1). Reptiles with similar lengths can be very different in body size. Thus, when comparing sizes across taxa weight is a much more reasonable measure, which is why we converted all lengths to masses.

We define brood size as the average number of eggs in a clutch or neonates in a litter. Sizes of neonates and hatchlings are masses (in g) reported at birth or hatching, or lengths converted to masses for squamates, as described above. Adult sizes are mean female masses. We record the mean number of clutches weighed per year.

For birds and mammals we obtained life history data from the large compilations reported above. For reptiles, however, we compiled the data ourselves (see e.g., [133, 141]). In many cases we had multiple data points per species per trait. In these cases, we averaged the smallest and largest reported means. When means were unavailable, we averaged the smallest and largest reported observation (for body size these are minimum and maximum sizes of adults).

We followed the August 2020 taxonomy of Reptile database for reptiles [142], the July 2020 taxonomy of IOC Bird List for birds [143] and the September 2020 taxonomy of Mammal Diversity Database for mammals [144]. We used the 'taxize' R package [145], and the Integrated Taxonomic Information System (ITIS 2020) to help resolve synonyms. For phylogenetic analysis, we followed the taxonomy of the phylogenies used. 

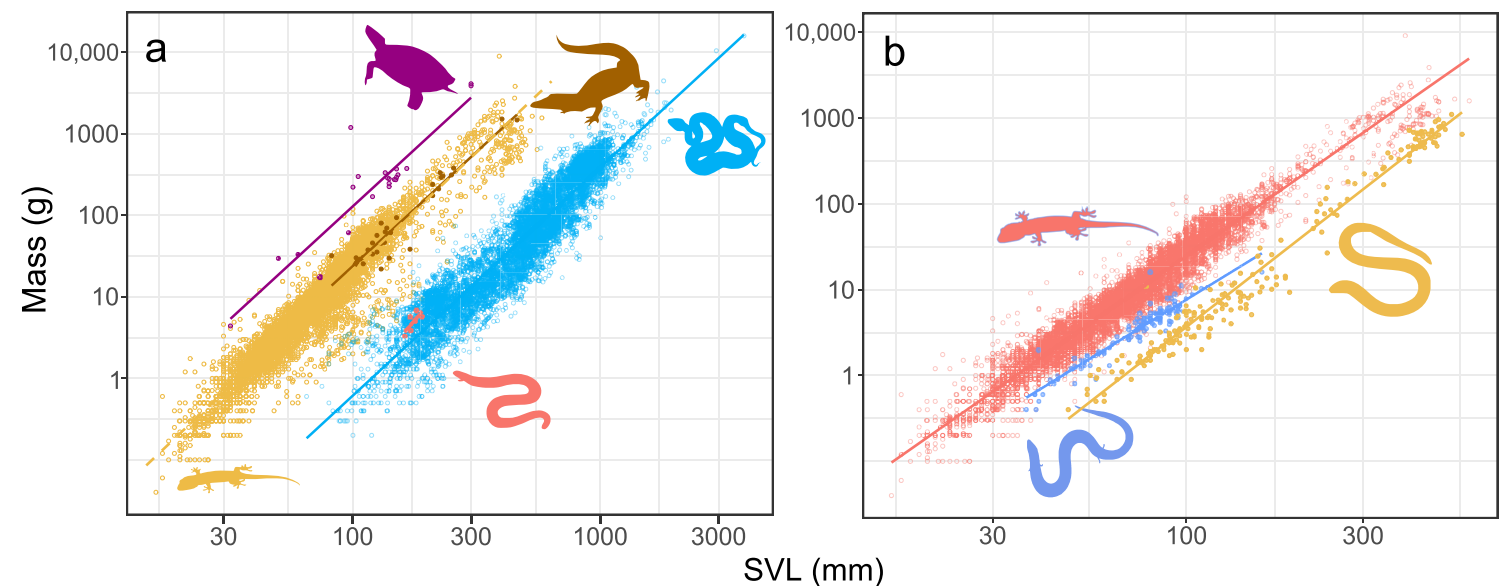

Fig. 1 The lengths and weights of specimens at the Steinhardt Museum of Natural History, Tel Aviv University a reptiles: 34 crocodiles (brown), 22 turtles (purple), 5110 snakes (blue), 7478 lizard (yellow) and 6 amphisbaenian (red) b only for lizards: colored according to leg development: fully developed (red), limb reduced (including two-limbed species; blue) and limbless species (yellow)

\section{Statistical analyses}

Because endothermy and obligatory parental provisioning (as well as flight) evolved only twice during the evolution of extant amniotes (in the common ancestors of mammals and birds, and flight in bats and birds) we are unable to meaningfully use phylogenetic comparisons for these traits. Such unique evolutionary events do not lend themselves to methods such as phylogenetic least square regression, as the number of degrees of freedom is effectively nil ([146], see also [147]). The inability to conduct meaningful phylogenetic comparisons of the impact of endothermy and parental care on life history strategies across amniote classes compelled us to use descriptive statistics and graphs to examine differences and similarities between them. To compare allometries between major tetrapod clades we used phylogenetic generalized least square regression (PGLS), implemented in the $R$ package CAPER [148]. In all PGLS analyses we estimated the strength of the phylogenetic signal using the maximum-likelihood parameter $\lambda$ and used this value to scale branch lengths [148]. To reduce heteroscedasticity and normalize residual distributions, all quantitative data (clutch and litter size, hatchling, neonate and adult female mass, and brood frequencies) were $\log _{10}$ transformed prior to analyses. In a couple of occasions [brood size allometry in mammals (Fig. 6) and allometry of relative brood mass (Fig. 10)], we depict the slopes using a Generalized Additive model instead of PGLS as visual examination of scatter plot revealed a non-linear relationship. We used taxonomy-imputed trees from Upham et al. [149] for Mammalia, Tonini et al. [150] for Squamata, Colston et al. [151] for Testudines, and Cooney et al. [152] for Aves to control for phylogenetic autocorrelation. We averaged the life history data of species which are represented by a single synonym in the phylogenetic tree and multiple synonyms in the life history data sets. We compared the phylogenetic signal, slopes, and intercepts of each trait's regression line between groups, as well as how much variation in each trait is explained by body size.

\section{Results}

\section{Comparisons of mammals, birds, and reptiles Body size}

Amniotes come in many different sizes, but class-level differences are readily apparent. Turtles are distinctively the largest (even the smallest species is larger than the median for all other clades), followed by mammals (which have the highest masses) then birds, and squamates are the smallest. The median-sized mammal, at $79.7 \mathrm{~g}$, weighs more than twice as much as a median size bird $(36.4 \mathrm{~g})$, and over 5 times the median size reptile (14.3 g; Table 1)-despite the fact that our estimates for reptiles are based on maximum sizes $([140,153]$, Additional file 1: Appendix S1) whereas those for mammals and birds are based on means. Thus, reptile sizes here are inflated by about a factor of about two (maximum species mass is, on average, 1.97 times mean female mass, over 4944 species of lizards; Meiri, unpublished).

The distributions of sizes within the three classes have similar shapes, all are unimodal and right-skewed (Fig. 2). That said, reptiles attain much smaller sizes than endotherms, and dominate size classes up to $\sim 10 \mathrm{~g}$, mammals attain the largest sizes, and dominate size classes $>1 \mathrm{~kg}$, whereas bird sizes are intermediate and less variable, and 
Table 1 Body masses of amniotes (g)

\begin{tabular}{|c|c|c|c|c|c|c|}
\hline & $\mathrm{n}$ & Mean & Median & Minimum & Maximum & $\begin{array}{l}\text { Orders } \\
\text { of magnitude }\end{array}$ \\
\hline Aves & 9281 & 51 & 36.4 & 1.9 & 109,250 & 4.8 \\
\hline Mammalia & 5364 & 197 & 79.7 & 1.6 & $190,000,000$ & 8.1 \\
\hline Squamata & 10,825 & 18.2 & 14.3 & 0.07 & 345,144 & 6.7 \\
\hline Testudines & 308 & 397 & 2804 & 93.1 & 950,000 & 4 \\
\hline
\end{tabular}

$\mathrm{n}=$ number of species with data. Means are back transformed from logarithms

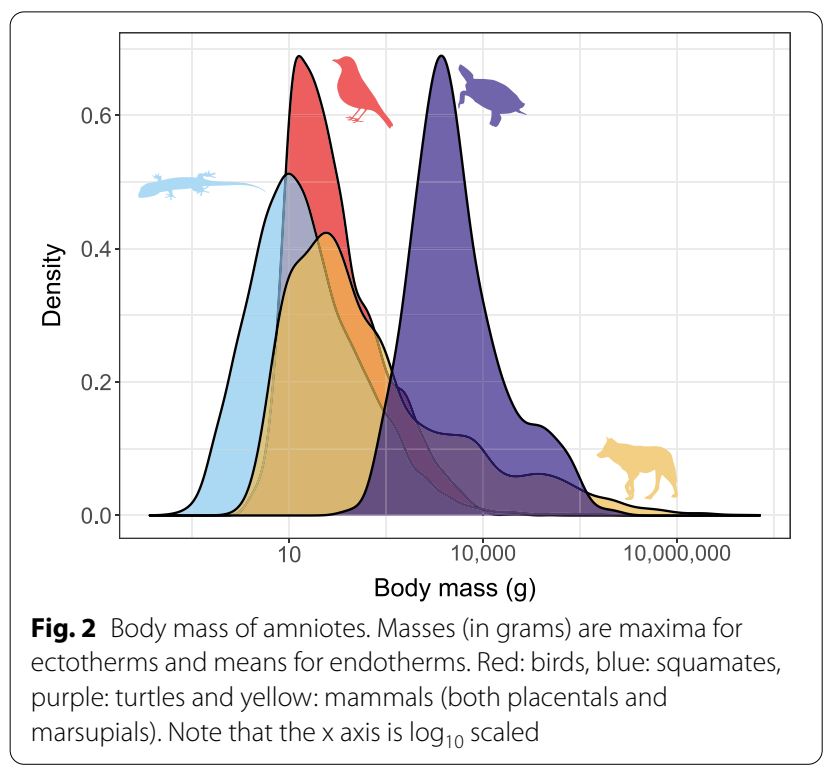

$67 \%$ of bird species occupy a size range between 10 and $180 \mathrm{~g}$ (Fig. 2).

\section{Offspring size}

Offspring mass increases with female mass across all clades (squamates: slope 0.631, intercept -0.748 , $\mathrm{R}^{2}=0.649, \quad \mathrm{n}=2073, \quad p<0.001, \quad \lambda=0.824 ; \quad$ birds: slope $=0.637$, intercept $=-0.353, \mathrm{R}^{2}=0.768, \mathrm{n}=716$, $p<0.001, \lambda=0.955$; placental mammals: slope 0.749 , intercept $=-0.477, \quad \mathrm{R}^{2}=0.771, \quad \mathrm{n}=1012, \quad p<0.001$, $\lambda=0.952$; Fig. 3) (see [154] for a discussion of the nuances of the interpretation of $\mathrm{R}^{2}$ in PGLS). That said, the allometric slopes for turtles (slope: 0.301, intercept 0.049, $\mathrm{n}=75, p<0.001, \lambda=0.879$ ) and marsupials (Metatheria; slope: 0.323 , intercept $-1.850, \mathrm{n}=52, p<0.001, \lambda=1$ ) are decidedly shallower, and the relationship weaker $\left(R^{2}=0.498\right.$ for turtles, $R^{2}=0.438$ for marsupials). The offspring/female size ratio is very similar across the three major groups: $8.2 \%$, on average, in both mammals and squamates, and $7.0 \%$ in birds, and shows remarkably similar distributions (Fig. 4). The mammal data hides great disparity between placentals (mean $8.6 \%$ ) and marsupials (mean $0.04 \%$ ). Turtles further deviate from the overall

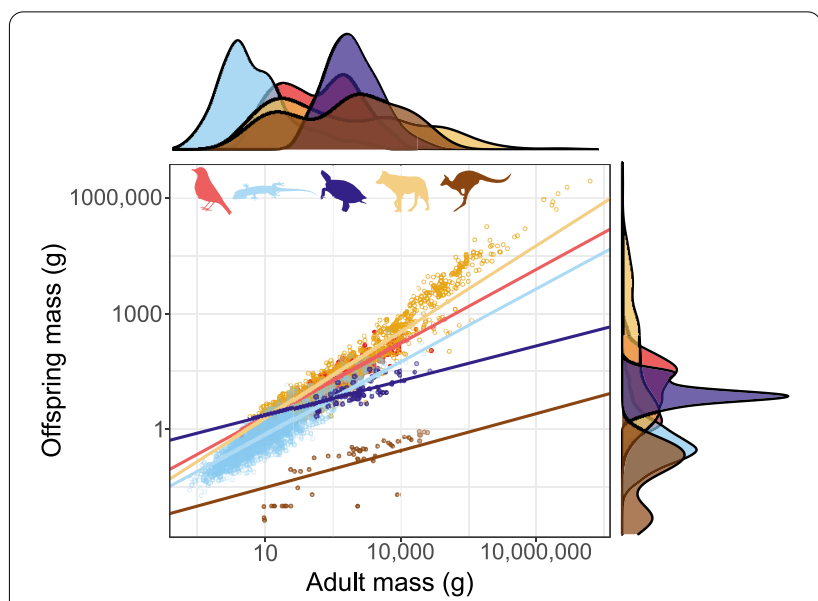

Fig. 3 Allometry of offspring size. Red: birds; blue: squamates; purple: turtles; yellow: placental mammals; brown: marsupial mammals. Solid lines are regression slopes from PGLS analysis. Both axes are $\log _{10}$ scaled

pattern having relatively small young (on average $1.3 \%$ of the mother size).

\section{Brood (clutch or litter) size}

Brood sizes are higher in squamates (mean 4.960; $\mathrm{n}=5131$ species $)$ than in birds $(3.1, \mathrm{n}=5297)$ and mammals have the smallest broods $(2.5, \mathrm{n}=2500)$. That said, the shape of the brood size distribution is similar overall (Fig. 5), with the mean distinction being that the mammalian mode is one neonate, whereas both birds and squamates have a mode of two hatchlings. From these modes the frequencies decrease as brood sizes increase in all three clades. Turtles are a clear exception, however, with very large clutches (12.1 eggs on average, $\mathrm{n}=294$ species) $-\mathrm{a}$ value only reached by $7.5 \%$ of squamates, $0.2 \%$ of birds, and three mammal species (Tenrec ecaudatus, Gracilinanus agilis, and Monodelphis dimidiata). However, major differences in reproductive allometry are apparent within the major above clades: in birds the relationship between $\left(\log _{10}\right)$ clutch size and $\left(\log _{10}\right)$ body mass is nearly flat in all taxa (Galloanserae: slope: $-0.035, \mathrm{R}^{2}=0.002, \mathrm{n}=288, p=0.446, \lambda=0.978$; Neoaves: slope: $-0.041, \mathrm{R}^{2}=0.005, \mathrm{n}=4943, p<0.001$, 


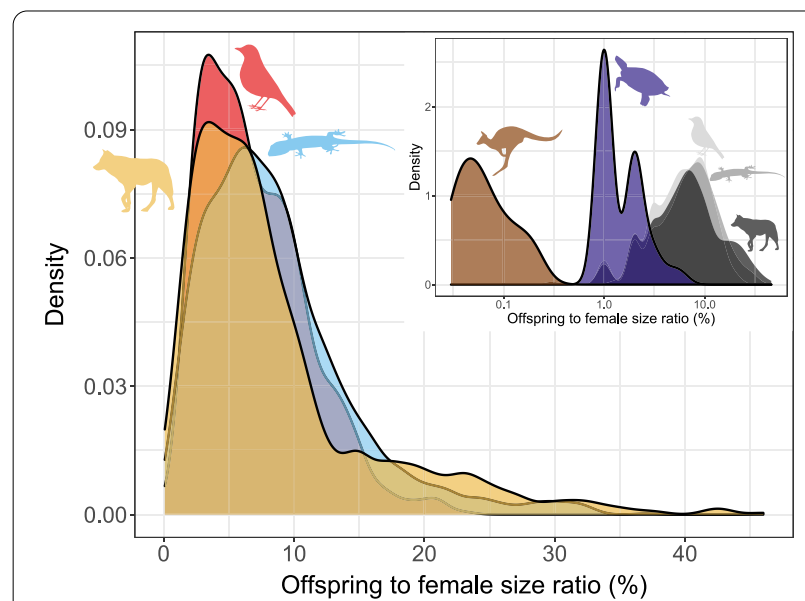

Fig. 4 Offspring size (expressed as \% of offspring size to the size of adult females). Red: birds; blue: squamates; purple: turtles; yellow: placental mammals; brown: marsupial mammals. Note that the $x$ axis is $\log _{10}$ scaled in the inset figure. Size ratio close to zero $(<0.03)$ only occur in marsupials (inset; values $<0.03$ not shown)

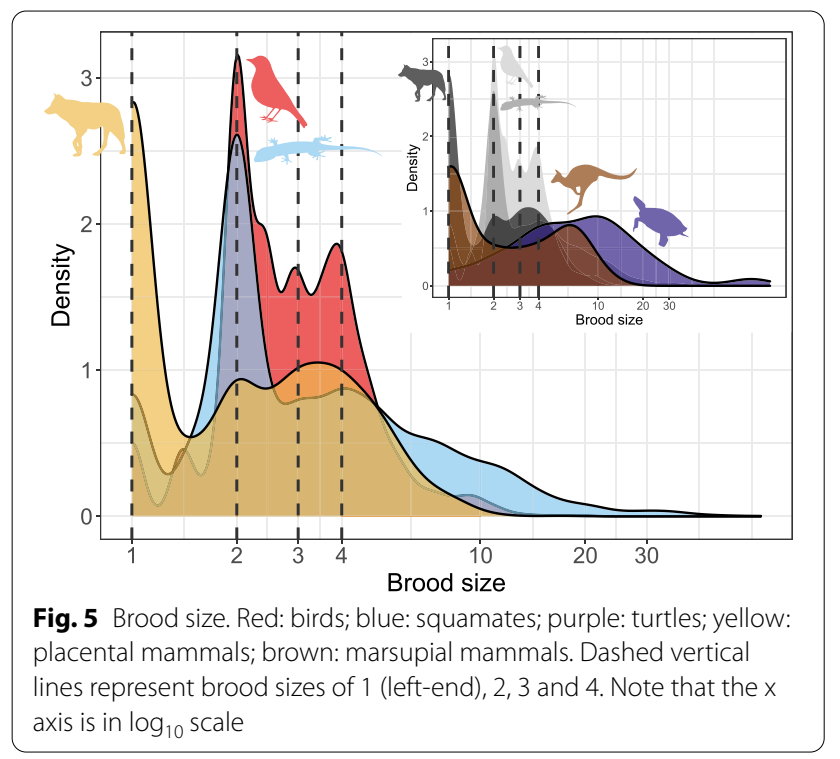

$\lambda=0.871$; Palaeognathae: slope: $0.125, \mathrm{R}^{2}=0.073, \mathrm{n}=36$, $p=0.111, \lambda=0.344)$. Clutch sizes are higher in Palaeognathae (mean 5.5) and, especially, in Galloanserae (mean 6.7) than in Neoaves $(2.9 \pm 1.2)$. In mammals, the relationship between litter size and body size is significantly negative, but very weak, in placentals (slope -0.015 , $\mathrm{R}^{2}=0.002, \mathrm{n}=2272, p=0.047, \lambda=0.949$ ), and marsupials (slope $-0.067, \mathrm{R}^{2}=0.044, \mathrm{n}=211, p=0.002, \lambda=0.994$ ). In placentals, the relationship is decidedly non-linear, and an apparent decline mainly seems to show decreased variance in litter sizes as body sizes increase. Nonetheless, marsupials have larger litters than placentals (3.2 vs 2.5). Finally, in the Squamata as a whole (slope 0.201, $\mathrm{R}^{2}=0.190, \mathrm{n}=3997, \quad p<0.001, \lambda=0.902$ ), in lizards (slope 0.186, $\mathrm{R}^{2}=0.155, \mathrm{n}=3692, p<0.001, \lambda=0.908$ ) and snakes (slope 0.260, $\mathrm{R}^{2}=0.374, \mathrm{n}=305, p<0.001$, $\lambda=0.787$ ) separately and, especially, in turtles (slope $0.399, \mathrm{R}^{2}=0.406, \mathrm{n}=283, p<0.001, \lambda=0.849$ ) clutch size increases with body size (Fig. 6). The average brood size of turtles (12.1) is also much larger than the squamate equivalent (4.9 \pm 5.3$)$.

\section{Reproductive frequency}

Ectotherms reproduce, on average, more frequently than endotherms. Turtles in our dataset $(n=182$ species) reproduce, on average, 2.28 times a year, and squamates 2.22 times $(\mathrm{n}=1584)$, while mammals $(\mathrm{n}=889)$ reproduce 1.88 times, and birds 1.46 times a year $(n=1784)$. High values for squamates, however, mostly represent anole reproduction in captivity. Of the 25 species reproducing 15 or more times a year (range: 15-28), 24 are anoles (the other is the sphaerodactylid gecko, Pristurus flavipunctatus which produced 78 clutches in 43 months in captivity, [155]). All these 25 species produce 1 egg per clutch. Without these data the average for Squamata is 1.93-similar to the mammalian mean. The median number of broods per year is one for Aves, (Neoaves: 1, Galloanserae: 1, Palaeognathae: 1.5), 1.5 for Squamata (Sauria: 1, Serpentes: 1.5) and Mammalia (Eutheria: 1.5, Metatheria: 1.4) and 2 for Testudines. Two of three species reproducing once every four years are snakes (the Arafura file snake, Acrochordus arafurae and the Shedao Island pitviper, Gloydius shedaoensis); the third is the sperm whale (Physeter catodon/macrocephalus). The median reproductive frequency is lower in birds (1 clutch a year) than in mammals and squamates ( 1.5 broods a year) and is the highest in turtles (2). The mode, and overall shape of the distributions are, however, extremely similar across birds, mammals and squamates (Fig. 7). In these three taxa the mode is one clutch or litter per year (in turtles the mode is 3), with a second, lower mode at two, and a distinct group of species reproducing once or twice a year. The frequencies decrease as the number of reproductive events per year increases. Although the modal reproductive frequency was the same for oviparous and viviparous squamates (one brood per year), oviparous squamates had higher median and mean reproductive frequency (1.5 and 1.9, respectively), then viviparous species ( 1 and 0.9; Fig. 8), with a significant difference in the means when controlling for body mass and phylogeny $(p=0.019)$.

Within birds, Galloanserae lay a little more frequently (mean 1.67 clutches a year) than either Palaeognathae or 

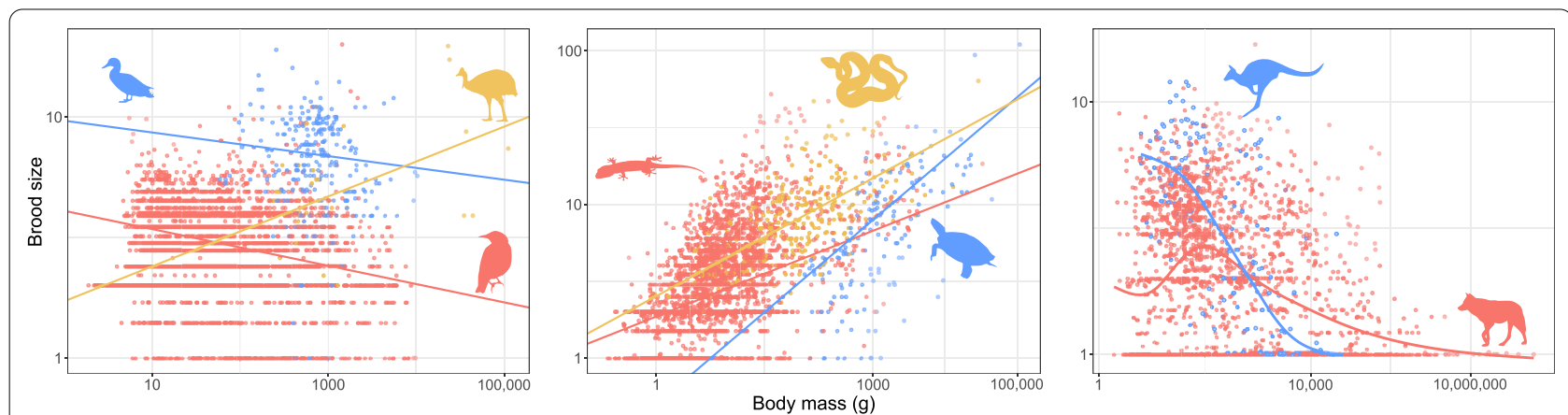

Fig. 6 Allometry of brood size. From left to right; a Aves (red: Neoaves, blue: Galloanserae, yellow: Palaeognathae), b Reptilia (red: Sauria, blue: Testudines, yellow: Serpentes) and c Mammalia (red: Eutheria; blue: Metatheria). Solid lines are regression slopes from PGLS analysis for Aves and Squamates. For Mammalia, regression lines are from a Generalized Additive model with knots $(k=10)$

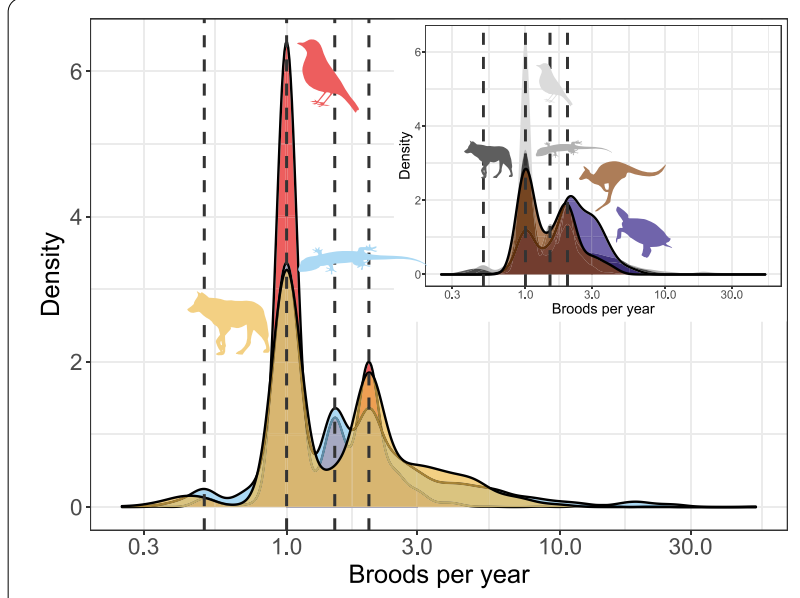

Fig. 7 Broods per year. Red: birds; blue: squamates; purple: turtles; yellow: placental mammals; brown: marsupial mammals. Dashed vertical lines represent $0.5,1,1.5$ and 2 broods per year. The $x$ axis is $\log _{10}$ scaled

Neoaves (1.43 in both). In mammals, placentals reproduce a little more frequently than marsupials (1.91 vs 1.60 litters year ${ }^{-1}$ ).

We highlight, however, that data on reproductive frequency is relatively scant. For example, the slowest reproducing species of amniotes are not in our database: the tuatara (Sphenodon punctatus) reproduces (almost) once every four years (e.g., [156]), while elephants reproduce even slower: Shoshani and Eisenberg [157] report that Asian elephants, Elephas maximus, reproduce once every 2.5-8 years, and Howard [158] reports 3-9 years for African elephants, Loxodonta africana. Data for elephant reproductive frequencies are absent from Jones et al. [104], and Sphenodon is not a squamate, therefore they were not analyzed here (Fig. 8).

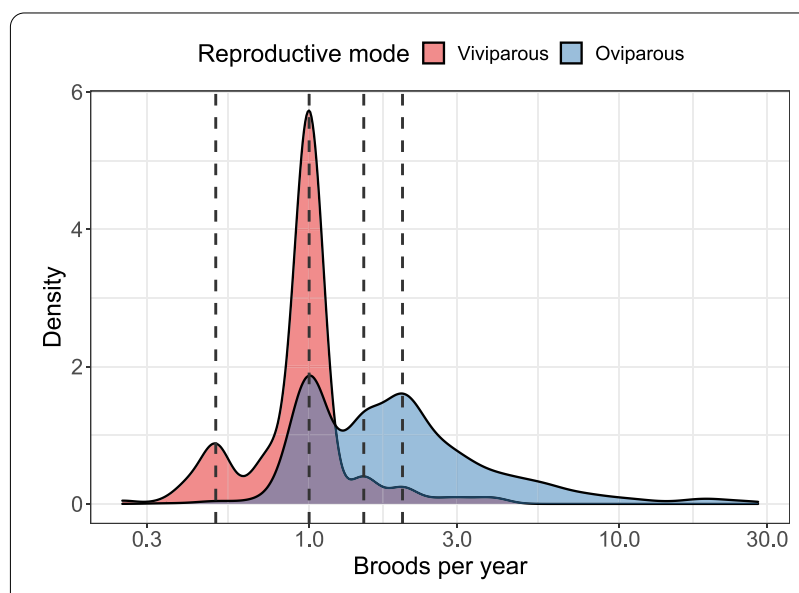

Fig. 8 Parity mode and broods per year for the Squamata. Dashed vertical lines represent (from left to right) $0.5,1,1.5$ and 2 broods per year. The $x$ axis is in $\log _{10}$ scale

\section{Relative brood mass}

Overall, the three major taxa are very similar, showing a similar spread of values (though no mammal has a relative brood mass higher than $70 \%$, whereas both birds and squamates have values close to 1 , Fig. 9). In both squamates and birds the most common values are between 10 and 25\%, but in eutherians lower values are also frequent, and the mode is $5-10 \%$. Turtle clutches weigh relatively little, with $89 \%$ of the species in our dataset have broods weighing less than $10 \%$ of the female size (Fig. 9). In marsupials, the weight of the litter does not exceed $2.2 \%$ in any of the species for which we have data and is always much smaller than the other groups (Fig. 9, inset).

Overall relative brood mass rapidly declines with increasing adult size in all taxa (Fig. 10). The weight of all offspring from a single brood, divided by female weight ('relative brood mass') varies greatly between less than $10 \%$ and nearly $100 \%$ of the size of the mother up to a maternal size of $\sim 100 \mathrm{~g}$ in eutherians and $\sim 1 \mathrm{~kg}$ 


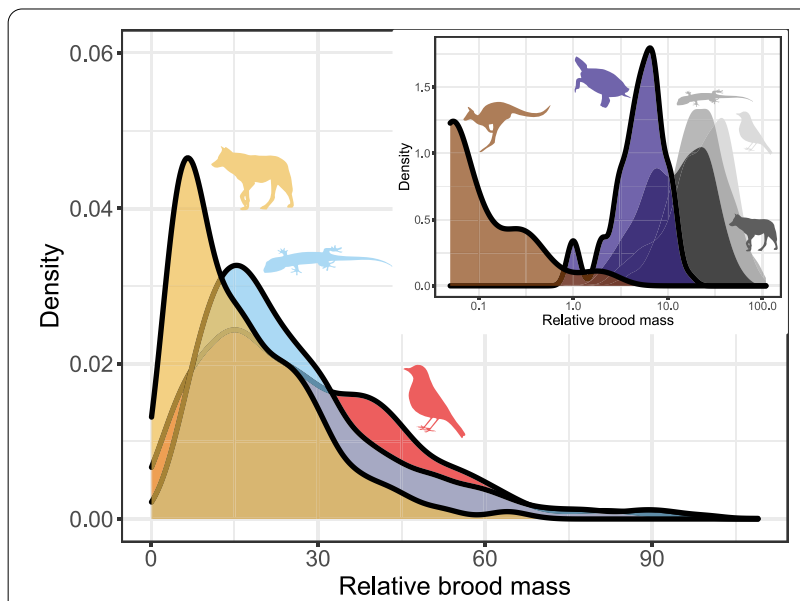

Fig. 9 Relative brood mass. Red: birds; blue: squamates; purple: turtles; yellow: placental mammals; brown: marsupial mammals. Note that the $x$ axis in the inset figure is $\log _{10}$ scaled

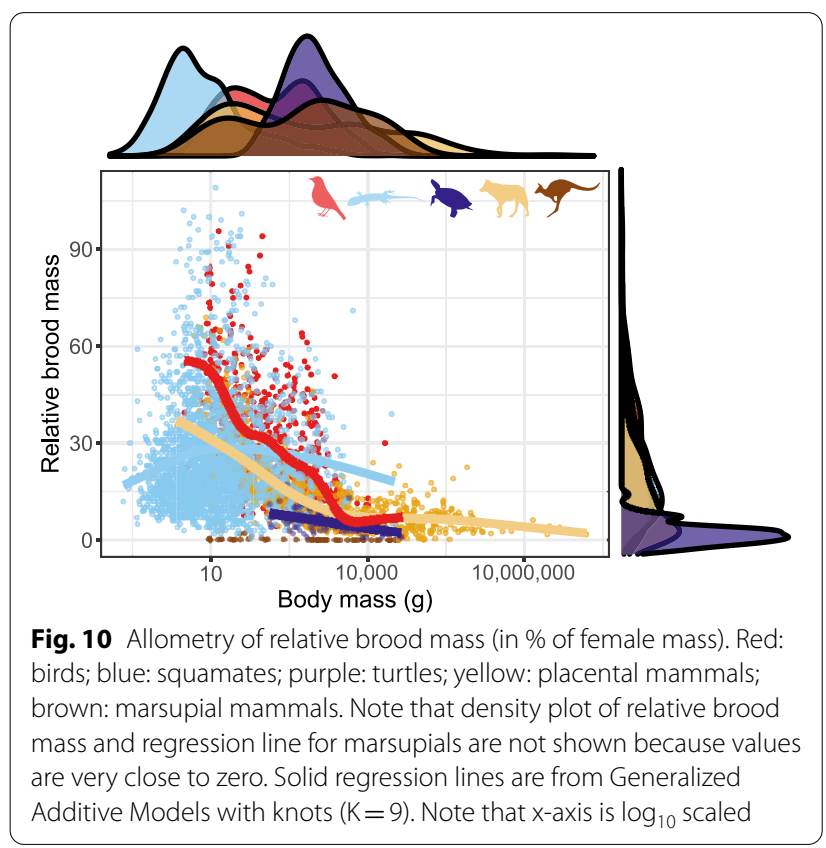

in squamates and birds. Mammals have lower values at all sizes and grow to much larger sizes than both birds and squamates. Thus, the average value $(0.163)$ is much lower in eutherians than in either squamates (0.265), or birds $(0.275)$, which are very similar to each other. Turtles (0.059) and, especially, marsupials (0.002) have much lower values still (Fig. 10).

\section{Yearly fecundity}

The number of offspring per year is highly variable, ranging from one offspring per three years in some whales, and one per two years in some sea birds, large raptors, and the amphisbaenian Blanus mettetali-to over 50 in all three classes. Placentals $\left(6.3 \pm 7.2\right.$ neonates year $^{-1}$, $\mathrm{n}=787)$ and marsupials $\left(6.9 \pm 5.5\right.$ neonates year $^{-1}$, $\mathrm{n}=84$ ) have similar yearly fecundity. In birds, Neoaves are much less fecund $\left(4.9 \pm 3.7\right.$ eggs year $\left.^{-1}, \mathrm{n}=1514\right)$, than members of the Galloanserae $(8.4 \pm 3.3, \mathrm{n}=246)$ and Palaeognathae $(9.4 \pm 5.5, \mathrm{n}=16)$. Within reptiles, squamates $(8.9 \pm 9.5, \mathrm{n}=1557$ species) are similar to the two latter bird groups, but turtles have by far the largest annual fecundities $(31.1 \pm 63.4, \mathrm{n}=181)$. Furthermore, while the mammalian mode is $1-2$ offspring per year, and higher values are increasingly less frequent, squamates and birds have a right-skewed distribution with a mode of 4-6 young, and turtles have no distinct mode but are generally characterized by much higher values than any other clade (Fig. 11).

In endotherms (birds, placentals and marsupials), larger-bodied species produce fewer offspring per unit time than smaller bodied ones, but larger ectotherms (turtles and squamates) out-produce smaller ones (Fig. 12).

\section{Rates of reproductive output}

Reproductive output rates, measured as the biomass of offspring hatching or being born in a year, are first and foremost tied to the size of the mother (Fig. 13). Compared across the amniote taxa the allometric slopes are somewhat dissimilar. They are shallowest in marsupials (slope: $0.179, \mathrm{R}^{2}=0.152, \mathrm{n}=43, \lambda=0.941$ ) followed by birds (slope: $0.549, \mathrm{R}^{2}=0.558, \mathrm{n}=978, \lambda=0.893$ ), steeper in placental mammals (slope: $0.689, \mathrm{R}^{2}=0.694$, $\mathrm{n}=467, \lambda=0.805$ ), and steeper still in turtles (slope: $0.816, \mathrm{R}^{2}=0.771, \mathrm{n}=75, \lambda=0.142$ ) and squamates (slope: $\left.0.806, R^{2}=0.633, n=1053, \lambda=0.753\right)$. The intercepts are

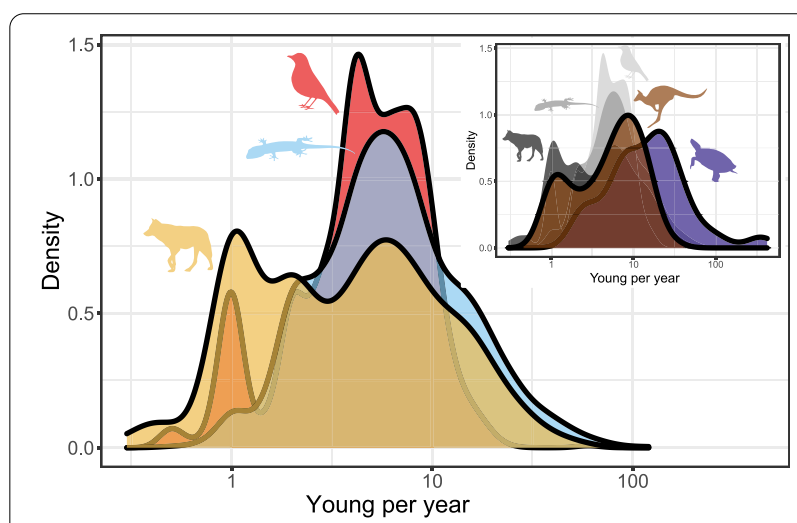

Fig. 11 Young per year. Red: birds; blue: squamates; purple: turtles; yellow: placental mammals; brown: marsupial mammals. Note that the $x$ axis is $\log _{10}$ scaled 


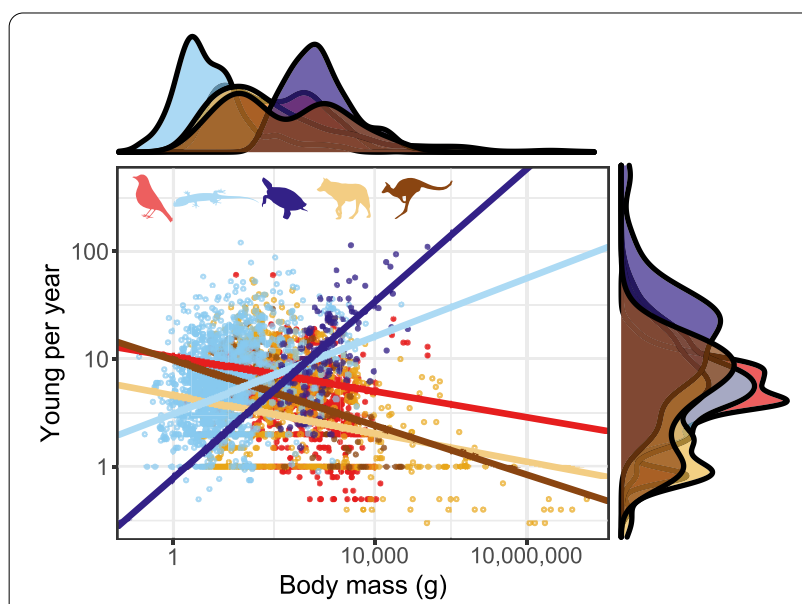

Fig. 12 Allometry of young per year. Red: birds; blue: squamates; purple: turtles; yellow: placental mammals; brown: marsupial mammals. Solid lines are regression slopes from PGLS analyses. Note that both the axes are $\log _{10}$ scaled

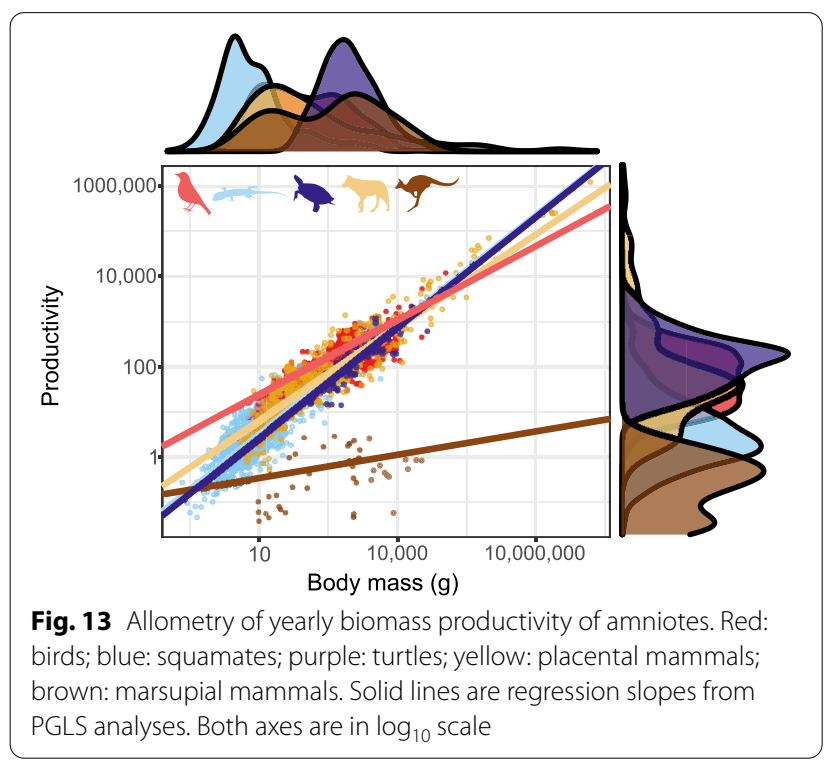

also dissimilar: 0.602 in birds, 0.115 in placental mammals $(p=0.420),-0.714$ in marsupials, -0.396 in turtles, and -0.319 in squamates. These values, however, suggest more overlap than the differences imply, as shallow slopes are associated with high intercepts. Thus, the regression lines intersect at values close to $1 \mathrm{~kg}$, where all classes are species-rich (Fig. 13). At somewhat smaller sizes, where most diversity resides in all taxa (except turtles), birds and mammals are somewhat more productive than squamates and, especially, turtles. That said, there is great overlap between all three major groups across the range of sizes where squamates, birds and mammals are most diverse (approximately 10-3000 g).
The overall patterns are quite similar across the three major amniote clades (Squamata, Aves and Eutheria) for most traits (Fig. 14), while members of the Metatheria and Testudines share similar values in some traits but differ markedly in others (Table 2).

\section{Discussion}

Amniotes are distinct from anamniote vertebrates in their physiology and reproduction physiology. The evolution of the cleidoic egg has put them on a path that enables successful reproduction on land. It allows the embryos to develop, grow, and exchange gasses with the environment without extensive risk of desiccation. The evolution of the extraembryonic membranes of amniotes may be imposing a constraint on the lower limit of amniote egg-or embryo sizes [12, 88]. This constraint is probably absent in our anamniote kin and thus anamniotes' eggs are often much smaller, even in large bodied species.

Amniotes then diversified into endotherms (twice), shelled ectotherms (once), and a major lepidosaur/squamate radiation that retained the primitive position of ectothermy without a shell. Endotherms evolved complex and prolonged thermal and food provisioning for their young, and often complex social systems, that reptiles mostly did not. Viviparity evolved multiple times, and within mammals takes two very distinct forms. All this, and more, certainly influenced the reproductive and life history characteristics of amniote taxa. Surprisingly, however, our hypotheses, that these major transitions will manifest in substantial quantitative differences between clades, were mostly refuted.

The evolution of endothermy and its abovementioned associated life-history traits, were unique evolutionary events (as is the evolution of the turtle shell). Claiming that endothermy is the cause of parental provisioning, or of inter-clade differences in the traits we study, is risky [99]. While associating the evolution of parental provisioning with endothermy is compelling [31], it is difficult to pinpoint endothermy as the cause of life history discrepancies without testing the myriad of other traits that evolved in mammals, birds, squamates, or turtles, during the hundreds of millions of years of their independent evolution. Furthermore, one is faced with a difficulty when analyzing the effects of such unique events quantitatively [146]. Because the species within each clade are not evolutionary independent units, the number of degrees of freedom for statistical analyses will be inflated if we treat each species level datum as an independent statistical entity. Phylogenetic comparative methods, on the other hand, are shackled by the few transitions to endothermy, and the non-independence of provisioning from endothermy. This may make them overly 

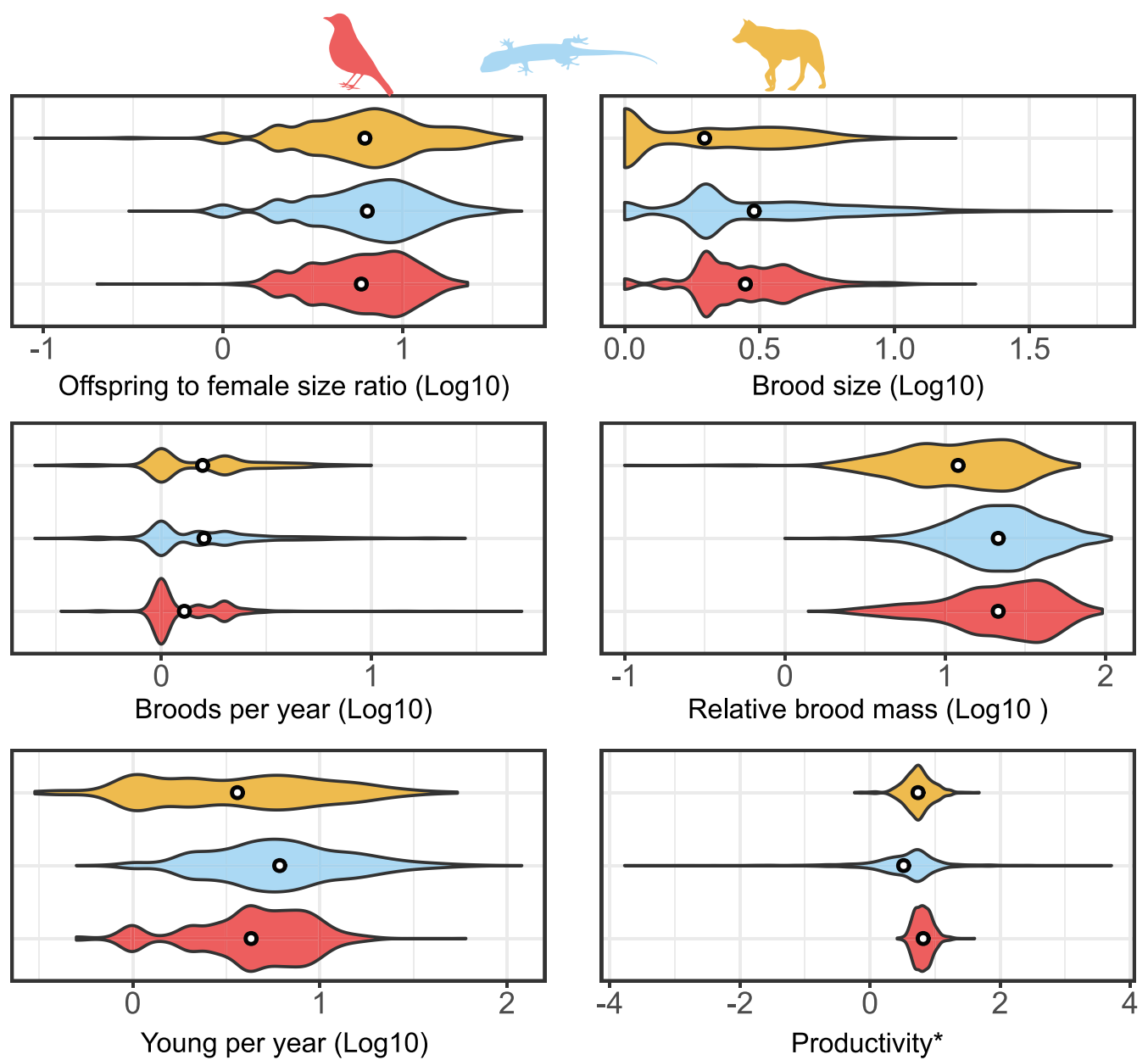

Fig. 14 Violin plots depicting the distribution of life history traits in the three major amniote clades. Means are represented as solid white points. Productivity expressed as the ratio of productivity (brood size $x$ brood frequency $\times$ offspring size) over adult body size to standardize for body size. Red: birds, blue: squamates, yellow: placental mammals. (See Additional file 2: Figure S1 for graphs that also include marsupials and turtles)

Table 2 Summary table comparing life history distribution across amniotes

\begin{tabular}{|c|c|}
\hline & Characteristics of distribution \\
\hline Body mass & $\begin{array}{l}\text { All unimodal and right skewed } \\
\text { Squamata }<\text { Aves }<<\text { Mammals }\end{array}$ \\
\hline Offspring/female size & $\begin{array}{l}\text { Offspring/female size ratio approximately the same across placental mammals, birds and squamates }(7-8 \%) \\
\text { marsupials }<<<\text { turtles }<<\text { birds } \approx \text { placentals } \approx \text { squamates }\end{array}$ \\
\hline Brood size & Mode is 1 in mammals, 2 in birds and squamates \\
\hline Reproductive frequency & The overall mode and distribution of reproductive frequency is extremely similar across amniote groups \\
\hline Relative brood mass & $\begin{array}{l}\text { All unimodal and right skewed. But no placental mammal has a relative brood mass higher than } 70 \% \text {. Small in turtles, very } \\
\text { small in marsupials }\end{array}$ \\
\hline Yearly fecundity & $\begin{array}{l}\text { Distribution of reptiles and birds very similar (right skewed distribution with a mode of } 4-6 \text { young). Mammalian mode is } 1-2 \\
\text { offspring per year }\end{array}$ \\
\hline Reproductive output & $\begin{array}{l}\text { Similar overall in squamates, birds and mammals (low intercepts associated with steep slopes), low intercept in turtles, very } \\
\text { low intercept, and shallow slope in marsupials }\end{array}$ \\
\hline
\end{tabular}


conservative. We therefore opted not to formally compare these trends across mammals, birds, squamates and turtles, but rather to view their overall patterns. We do not doubt that there are inter-clade differences in most of the traits we examined, and that many differences that will be deemed 'statistically significant', and will result in models with relatively low AIC values, etc. We contend, however, that the overall picture is of great similarity across the major amniote taxa (Aves, Theria, Squamata) in most of the traits we examined.

Offspring sizes increase linearly with adult (or female) masses in placentals, birds and squamates, and the offspring are generally of similar size relative to that of the mother (Fig. 4). Brood sizes have similar modes and distributions, with the caveats that a litter of one is the mode in mammals, but two in birds and squamates-and very large broods are much more common in squamates and, especially, turtles. Most taxa in all clades reproduce once or twice a year (Fig. 5). Again, some squamate groups (usually with a clutch of one or two eggs, e.g., anoles) are 'outliers'. But most taxa share very similar values across classes. We suspect that similar frequencies may characterize other vertebrate and potentially invertebrate taxa as well.

Bird and squamate clutches are also very similar in terms of their mass relative to that of the mother (Fig. 9). This is despite the avian eggs losing water during incubation [159] while the eggs of most squamates take up water from the environment ([160]; though some reptile clades, such as most gekkotans, are more bird-like in this respect). This is even more surprising given that birds develop their eggs sequentially within a single clutch while squamate eggs belonging to the same clutch develop simultaneously within the mother's reproductive tract [161]. Placental litter masses are smaller, both relative to the size of the adults, and because of the abundance of very large mammals coupled with the negative relationship between body size and relative litter mass. An additional reason may be the extra weight of the complex placenta and associated tissues. That said, viviparous and oviparous squamates do not differ in this respect [72]. Yearly fecundity shows much variation across taxa. Though birds and squamates are quite similar overall, there are large differences between major avian clades, and between major squamate clades.

Given the overall similarities, the fact that biomass of offspring produced by a female in a year is so similar across clades, when viewed in term of its relationship with the mass of the females (especially across a similar range of female masses), could be expected. It seems as if the major differences in reproductive physiology between these taxa and hundreds of millions of years of subsequent independent evolution, had surprisingly little effect on the quantitative traits that we examined (Fig. 13; see also [162]). While the paths may differ greatly, some fundamental constraints impose overall similar outcomes, despite very different 'solutions' and adaptations.

Two deeply divergent lineages, however, depart much from their relatives. Turtles differ both from birds (their sister clade) and from squamates (while sharing their ectothermic physiology). Turtles reproduce frequently, which is even more remarkable given their large size (and perceived overall slowness). They also lay many small eggs per clutch. Despite this, they have low relative clutch masses: the large clutch size does not fully compensate for the small size of the hatchlings. Thus, turtles also have low rates of biomass production. Turtles have a very long independent evolutionary history, and thus differ from other amniotes in many traits. It is nonetheless tempting to advocate that the life history discrepancy we identify between turtles and other amniotes is caused by the hallmark of turtle-ness, their shell. We hypothesize that the evolution of the rigid shell imposes an upper limit on egg size. This is of course not a new hypothesis (one can find it in textbooks, e.g., [68]), but we only found it studied within turtle species, and across small groups of closely related species, that do not span the size range of turtles as a whole (e.g., [163]). Interestingly, both Congdon and Gibbons [163], and Rollinson and Brooks [164], identified such constraints to be stronger in small species, and small females, respectively, whereas the shallow egg size-body size allometric slope we obtained suggest that larger species may be more strongly constrained. Janzen and Warner [165] found that offspring fitness was maximized at larger egg size than the size which maximized maternal fitness. Furthermore, they found that actual egg sizes were closer to the maternal than to the offspring optimum, suggesting that selection on turtle egg size was driven by selection on the females rather than on their offspring [165]. Our results agree with this suggestion. We hypothesize that the constraint on egg sizes in turtles has strong downstream implications for the evolution of clutch size and clutch frequency. Beyond the external shell of tortoises, greater egg production may be limited by calcium requirements [166-168]. Calcium is needed for skeletal development and maintenance, and for egg-shell production [169]. Calcium requirements for egg production is higher for when many small eggs than for a few large ones of the same volume. Therefore, both limits on egg size and their numbers could potentially explain the unique pattern we identify in turtle reproduction (which may be more similar to what is found in some anamniote taxa) compared with other amniotes. 
Marsupial reproductive traits are even more distinct than those of turtles. The tiny offspring of metatherians are much smaller than those of all other amniotes, regardless of their adult size. Interestingly, this does not seem to allow marsupials to have large litters, and indeed the decline in litter size with body size is stronger in marsupials than in placentals. Nor do metatherians reproduce more frequently-if anything they reproduce less often than placentals. Thus, their clutch masses, and annual biomass production, are much lower than in any of the other groups. If any groups of amniotes evolved a completely unique set of life history characteristics it is most probably marsupials. The huge discrepancy between the reproduction of marsupials and other amniotes may mean that some of the comparisons we made do not strictly contrast like with like. While the traits we chose are similar and easy to quantify across taxa, the extra 'gestation' of metatherian neonates in the mother's pouch makes them physiologically and ecologically different to those of other taxa. Furthermore, the provisioning of young by mammals, and most birds, in the first stages of their lives may also mean that a more valid comparison with reptile offspring should be made at the weaning or fledgling stages. This however necessitates quantifying the rates of survival from birth and laying to weaning and fledgling and may also not be strictly comparable across taxa.

One way or another, marsupials differ much from placentals, and from all other amniotes, in the size of their neonates. Hamilton et al. [102], however, have shown that in terms of weaning mass, lifespan and, at least for large species, the time since conception to weaning and age at first reproduction, marsupials and placentals are remarkably similar. Thus, the very different way marsupials go about their reproduction again results in great similarities between them and placental mammals, if not other amniotes (or even vertebrates) in general.

Similar to the marsupial/placental contrast, deep splits in the avian and squamate trees of life do result in differences in traits such as those we studied here. For example, palaeognaths are more similar to reptiles (and much of the animal world) in having a positive clutch size/ body size allometry, whereas neognaths have a basically flat (or slightly negative) allometry. This suggests that the forces affecting the relation between body size and clutch size evolved after the Palaeognathae/Neognathae split. However, members of both the Palaeognathae and Galloanserae lay more eggs than Neoaves birds, despite the Galloanserae being more closely related to the Neoaves.

Invariably there would be further differences between subclades the lower we go in the phylogenetic hierarchy. We did not attempt to quantify data for crocodiles or monotremes, because such small groups do not lend themselves easily to the type of generalizations we aimed to make. Nonetheless, differences in reproductive characteristics within major clades are well known. These include, for example, the small litter sizes and long lifespans of bats relative to other mammals [170, 171], and the fixed small clutches, and frequent laying of anoles and geckos $[99,133]$. Overall, though, endothermy, and parental provisioning, do not seem to impose great constraints on traits such as brood size, offspring size, reproduction frequency, and their derivatives such as annual fecundity, relative brood mass and annual biomass production. This is reflected both in the similar ranges, modal values, and similar distributions of the traits we analyze. We are therefore more impressed with the overall similarities, than with the differences across taxa.

What then does explain the huge variation, observed in all major taxa, across the life history traits we examined? Body size is an obvious candidate and has long been known to be associated with life history traits (e.g., $[76,77])$. We suspect that geography, manifested via climate and differences in species richness and guild composition (e.g., via insularity), are additional factors that affect vertebrate reproduction and aging. The effects of climate on life history traits have been a subject of extensive research, especially in birds (e.g., [172-175], see also Iverson [176] for turtles and Meiri et al. [58, 97] for lizards). One can wonder, for example, whether marsupials grow slowly [102], and reproduce less frequently (see above), than placentals because of their different reproductive physiology_or because most species (especially most species for which data are available) reside in Australia. Australia has relatively few mammal species (e.g., [177]), but an overabundance of lizards which is often thought to be a consequence of the nutrient poor conditions in much of the continents [178-182]. Yom-Tov [113] has shown that Australian passerines, especially from lineages that have colonized the continent early ('old endemics'), reproduce more slowly than N. American passerines. A comparison between marsupials and placentals in Australia and South America is an obvious test of this hypothesis but is beyond the scope of this work.

We suspect that seasonality constrains the length of vertebrate activity season, influencing reproductive patterns. In more seasonal climates one option is to delay maturation, and potentially hibernate during the less suitable season. Alternatively, development may accelerate so animals are reproductively active by the onset of winter-or when they emerge in spring. Birds, for example, follow the second option, fledging early at high latitudes in very seasonal climates [119, 183].

Vertebrate zoologists often identify themselves as herpetologists, ichthyologists, ornithologists, or 
mammologists. Therefore, studies within classes are common, whereas cross-taxon, especially cross-class studies are rare (but see e.g., [90, 121, 162, 184, 185]). In biogeography and conservation, however, studies of terrestrial vertebrates are relatively common, as maps for all four classes and conservation statuses for (nearly) all amphibians, birds and mammals are thought to be available (though completeness varies). In terms of traits, however, the scarcity of cross-taxon studies therefore means we often have little feel for the similarities-or differences across taxa. We hope we have shown here that there is little reason why this should be the case. For us, the similarities were much more impressive than the differences that the fundamental divisions of physiology, locomotion, parental care, and sociality suggested would be the case. We hypothesize that the evolution of the cleidoic egg was the most influential step setting amniotes apart from anamniotes. Whether the differences between these two groups stretches to more than differences in clutch and offspring sizes remains to be explored. We hope studies across amniote, tetrapod, and vertebrate clades (and even across vertebrates and invertebrates) will become much more common.

\section{Supplementary Information}

The online version contains supplementary material available at https://doi. org/10.1186/s40709-021-00134-9.

Additional file 1: Appendix S1. Amniote body sizes.

Additional file 2: Figure S1. Reproductive characteristics of birds, squamates, turtles, placentals, marsupials and turtles.

\section{Acknowledgements}

We thank Rick Shine, Damien Esquerré, Ian Brennan, Martin Whiting, Dave Chapple and Octavio Jiménez Robles for valuable discussion. Anat Feldman and Rachel Schwarz helped with obtaining data for squamates. We thank Pasquale Raia and an anonymous referee for comments on an earlier version of the manuscript.

\section{Authors' contributions}

SM conceived of the study, and led the writing and data compilation. YI, AZ and LS collected additional data, GC carried out most of the analyses, GM created the figures, SM, UR, AZ, YI, GC and GM participated in formulating the ideas and writing the paper. All authors read and approved the final manuscript.

\section{Funding}

This study was funded by an ISF grant \#406/19 to UR and SM, which also funds the scholarships of AZ, GC and GM.

\section{Availability of data and materials}

All data used in this paper appear in Additional file 1: Appendix S1, or were already published (and full citations are provided)

\section{Ethics approval and consent to participate}

We declare no ethics approval is needed for this review as no experiments or observations were carried out, and all data are derived from the literature.
Consent for publication

Not applicable.

\section{Competing interests}

The authors declare that they have no competing interests.

\section{Author details \\ ${ }^{1}$ School of Zoology, Tel Aviv University, 6997801 Tel Aviv, Israel. ${ }^{2}$ The Steinhardt Museum of Natural History, Tel Aviv University, 6997801 Tel Aviv, Israel. ${ }^{3}$ Mitrani Department of Desert Ecology, The Jacob Blaustein Institutes for Desert Research, Ben Gurion University of the Negev, Midreshet Ben Gurion, Israel. ${ }^{4}$ Leibniz-Institute of Freshwater Ecology and Inland Fisheries (IGB), 12587 Berlin, Germany. ${ }^{5}$ Institute of Biology, Freie Universität Berlin, 14195 Berlin, Germany.}

Received: 7 December 2020 Accepted: 15 January 2021

Published online: 08 February 2021

References

1. Kardong KV. Vertebrates. Comparative anatomy, function, evolution. 7th ed. New York: McGrow-Hill; 2014.

2. Lambert $Y$. Why should we closely monitor fecundity in marine fish populations. J Northwest Atl Fish Sci. 2008;41:93-106.

3. May AW. Fecundity of Atlantic cod. J Fish Res Board Can. 1967;24:1531-51.

4. Haldorson L, Love M. Maturity and fecundity in the rockfishes, Sebastes spp., a review. Mar Fish Rev. 1991;53:25-31.

5. Thibault RE, Schultz RJ. Reproductive adaptations among viviparous fishes (Cyprinodontiformes: Poeciliidae). Evolution. 1978;32:320-33.

6. Winemiller KO, Rose KA. Patterns of life-history diversification in North American fishes: implications for population regulation. Can J Fish Aquat Sci. 1992;49:2196-218.

7. Yeager A, Commito J, Wilson A, Bower D, Schwarzkopf L. Sex, light, and sound: location and combination of multiple attractants affect probability of cane toad (Rhinella marina) capture. J Pest Sci. 2014;87:323-9.

8. Oliveira BF, São-Pedro VA, Santos-Barrera G, Penone C, Costa GC. AmphiBIO, a global database for amphibian ecological traits. Sci Data. 2017:4:170123.

9. Amphibia Web; 2020. https://amphibiaweb.org. Accessed Jan 2020

10. Santos JT. Natural history of Rhinella jimi (Anura; Bufonidae): an invasive species in Fernando de Noronha [MSc. thesis]. Universidade Estadual de Campinas; 2011.

11. Diamond AW. Breeding biology and conservation of hawksbill turtles, Eretmochelys imbricata L., on Cousin Island, Seychelles. Biol Conserv. 1976;9:199-215.

12. Kratochvíl L, Frynta D. Body-size effect on egg size in eublepharid geckos (Squamata: Eublepharidae), lizards with invariant clutch size: negative allometry for egg size in ectotherms is not universal. Biol J Linn Soc. 2006:88:527-32.

13. Barclay RMR. Constraints on reproduction by flying vertebrates: energy and calcium. Am Nat. 1994;144:1021-31.

14. Sibly RM, Witt CC, Wright NA, Venditti C, Jetz W, Brown JH. Energetics, lifestyle, and reproduction in birds. Proc Natl Acad Sci USA. 2012;109:10937-41.

15. Nagy KA, Girard IA, Brown TK. Energetics of free-ranging mammals, reptiles and birds. Annu Rev Nutr. 1999;19:247-77.

16. Lavigne DM. Similarity in energy budgets of animal populations. J Anim Ecol. 1982;51:195-206.

17. Wieser W. A new look at energy conversion in ectothermic and endothermic animals. Oecologia. 1985;66:506-10.

18. Bonnet X, Bradshaw D, Shine R. Capital versus income breeding: an ectothermic perspective. Oikos. 1998:83:333-42.

19. Clarke A. Energy flow in growth and production. Trends Ecol Evol. 2019;34:502-9.

20. Burton TM, Likens GE. Energy flow and nutrient cycling in salamander populations in the Hubbard Brook experimental forest. $\mathrm{N}$ Hampshire Ecol. 1975;56:1068-80.

21. Pough FH. The advantages of ectothermy for tetrapods. Am Nat. 1980;115:92-112. 
22. King B, Lee MSY. Ancestral state reconstruction, rate heterogeneity, and the evolution of reptile viviparity. Syst Biol. 2015;64:532-44.

23. Moore JR, Varricchio DJ. The evolution of diapsid reproductive strategy with inferences about extinct taxa. PLoS ONE. 2016;11:e0158496.

24. Farmer CG. Parental care: the key to understanding endothermy and other convergent features in birds and mammals. Am Nat. 2000;155:326-34.

25. Case TJ. Endothermy and parental care in the terrestrial vertebrates. Am Nat. 1978:112:861-74

26. Gans C. An overview of parental care among the Reptilia. Adv Study Behav. 1996:25:145-57.

27. Halliwell B, Uller T, Holland BR, While GM. Live bearing promotes the evolution of sociality in reptiles. Nat Commun. 2017;8:2030.

28. Shine R. Parental care in reptiles, Ecology B. Defense and life history. In: Gans C, Huey RB, editors. Biology of the Reptilia, vol. 16. New York: Liss; 1988. p. 275-330.

29. Doody JS, Freedberg S, Keogh JS. Communal egg-laying in reptiles and amphibians: evolutionary patterns and hypotheses. Q Rev Biol. 2009;84:229-52

30. While GM, Halliwell B, Uller T. The evolutionary ecology of parental care in lizards. In: Rheubert JL, Siegel DS, Trauth SE, editors. Reproductive biology and phylogeny of reptiles. Enfield: Science Publishers; 2015. p. 590-620.

31. Beekman $\mathrm{M}$, Thompson $\mathrm{M}$, Jusup $\mathrm{M}$. Thermodynamic constraints and the evolution of parental provisioning in vertebrates. Behav Ecol. 2019;30:583-91.

32. Balshine S. Patterns of parental care in vertebrates. In: Royle NJ, Smiseth PT, Kölliker M, editors. The evolution of parental care. Oxford: Oxford University Press; 2012. p. 62-80.

33. Watson GS, Green DW, Watson JA. Observations supporting parental care by a viviparous reptile: aggressive behaviour against predators demonstrated by Cunningham's skinks. Aust J Zool. 2020;67:180-3.

34. Trillmich F. Are endotherms emancipated? Some considerations on the cost of reproduction. Oecologia. 1986;69:631-3.

35. Gregory PT. Northern lights and seasonal sex: the reproductive ecology of cool-climate snakes. Herpetologica. 2009;65:1-13.

36. Zhang L, Guo K, Zhang GZ, Lin LH, Ji X. Evolutionary transitions in body plan and reproductive mode alter maintenance metabolism in squamates. BMC Evol Biol. 2018;18:45

37. Stearns SC. Life-history tactics: a review of the ideas. Q Rev Biol. 1976;51:3-47.

38. Bruton MN. Trends in the life-history styles of vertebrates: an introduction to the second ALHS volume. Environ Biol Fishes. 1990;28:7-16.

39. Winemiller KO. Life history strategies, population regulation, and implications for fisheries management. Can J Fish Aquat Sci. 2005;62:872-85.

40. Duellman WE. Alternative life-history styles in anuran amphibians: evolutionary and ecological implications. Dordrecht: Springer; 1989. p. $101-26$.

41. Crump ML. Parental care among the amphibia. In: Advances in the study of behavior. Amsterdam: Elsevier; 1996. p. 109-44.

42. Wake MH. Fetal adaptations for viviparity in amphibians. J Morphol. 2015;276:941-60.

43. Vági B, Végvári Z, Liker A, Freckleton RP, Székely T. Parental care and the evolution of terrestriality in frogs. Proc Biool Sci. 2019;286:20182737.

44. Tinkle DW, Wilbur HM, Tilley SG. Evolutionary strategies in lizard reproduction. Evolution. 1970;24:55-74.

45. Dunham AE, Miles DB, Reznick DN, Ecology B. Life history patterns in squamate reptiles. In: Gans C, Huey RB, editors. Biology of the Reptilia. New York: Liss; 1988. p. 441-522.

46. Wourms JP, Lombardi J. Reflections on the evolution of piscine viviparity. Am Zool. 1992;32:276-93.

47. Gross MR, Sargent RC. The evolution of male and female parental care in fishes. Am Zool. 1985;25:807-22.

48. Sargent RC, Taylor PD, Gross MR. Parental care and the evolution of egg size in fishes. Am Nat. 1987;129:32-46.

49. Vila-Gispert A, Moreno-Amich R, García-Berthou E. Gradients of lifehistory variation: an intercontinental comparison of fishes. Rev Fish Biol Fisher. 2002;12:417-27.

50. Summers K, Sea McKeon C, Heying H. The evolution of parental care and egg size: a comparative analysis in frogs. Proc R Soc Lond B. 2006:273:687-92.
51. Summers K, McKeon CS, Heying H, Hall J, Patrick W. Social and environmental influences on egg size evolution in frogs. J Zool. 2007;271:225-32.

52. Kupfer A, Maxwell E, Reinhard S, Kuehnel S. The evolution of parental investment in caecilian amphibians: a comparative approach. Biol J Linn Soc. 2016;119:4-14.

53. Goodwin NB, Dulvy NK, Reynolds JD. Life-history correlates of the evolution of live bearing in fishes. Philos Trans R Soc Lond B Biol Sci. 2002:357:259-67.

54. Meiri S. Endothermy, offspring size and evolution of parental provisioning in vertebrates. Biol J Linn Soc. 2019;128:1052-6.

55. Baylis JR. The evolution of parental care in fishes, with reference to Darwin's rule of male sexual selection. Environ Biol Fish. 1981;6:223-51.

56. Shine R. Life-history evolution in reptiles. Annu Rev Ecol Evol Syst. 2005;36:23-46.

57. Meiri S, Brown JH, Sibly RM. The ecology of lizard reproductive output. Glob Ecol Biogeogr. 2012;21:592-602.

58. Meiri S, Bauer AM, Chirio L, Colli GR, Das I, Doan TM, et al. Are lizards feeling the heat? A tale of ecology and evolution under two temperatures. Glob Ecol Biogeogr. 2013;22:834-45.

59. Gunderson DR. Trade-off between reproductive effort and adult survival in oviparous and viviparous fishes. Can J Fish Aquat Sci. 1997;54:990-8.

60. Vila-Gispert A, Moreno-Amich R, Garcia-Berthou E. Gradients of lifehistory variation: an intercontinental comparison of fishes. Rev Fish Biol Fisher. 2002;12:417-27.

61. Amat F, Meiri S. Geographical, climatic and biological constraints on age at sexual maturity in amphibians. Biol J Linn Soc. 2018;123:34-42.

62. Scharf I, Feldman A, Novosolov M, Pincheira-Donoso D, Das I, Böhm M, et al. Late bloomers and baby boomers: ecological drivers of longevity in squamates and the tuatara. Glob Ecol Biogeogr. 2015;24:396-405.

63. Shine R. Propagule size and parental care: the "safe harbor" hypothesis. J Theor Biol. 1978;75:417-24.

64. Chen CK, Chuang HF, Wu SM, Li WH. Feather evolution from precocial to altricial birds. Zool Stud. 2019;58:24.

65. Crawford NG, Faircloth BC, McCormack JE, Brumfield RT, Winker K, Glenn TC. More than 1000 ultraconserved elements provide evidence that turtles are the sister group of archosaurs. Biol Lett. 2012:8:783-6.

66. Irisarri I, Baurain D, Brinkmann H, Delsuc F, SIre JY, Kupfer A, et al. Phylotranscriptomic consolidation of the jawed vertebrate timetree. Nat Ecol Evol. 2017;1:1370-8.

67. Gemmell NJ, Rutherford K, Prost S, Tollis M, Winter D, Macey RJ, et al. The tuatara genome reveals ancient features of amniote evolution. Nature. 2020;584:403-9.

68. Vitt LJ, Caldwell JP. Herpetology. 4th ed. London: Elsevier; 2013.

69. Shine R. The evolution of oviparity in squamate reptiles: an adaptationist perspective. J Exp Zool B Mol Dev Evol. 2015;324:487-92.

70. Seigel RA, Fitch HS. Ecological patterns of relative clutch mass in snakes. Oecologia. 1984;61:293-301.

71. Recknagel H, Elmer KR. Differential reproductive investment in cooccurring oviparous and viviparous common lizards (Zootoca vivipara) and implications for life history trade offs with viviparity. Oecologia. 2019:190:85-98.

72. Meiri S, Feldman A, Schwarz R, Shine R. Viviparity does not affect the numbers and sizes of reptile offspring. J Anim Ecol. 2020;89:360-9.

73. Feldhamer GA, Drickamer LC, Vessey SH, Merritt JF, Krajewski C. Mammalogy: adaptation, diversity, ecology. 3rd ed. Baltimore: Johns Hopkins University Press; 2007.

74. Tyndale-Biscoe H, Renfree M. Reproductive physiology of marsupials. Cambridge: Cambridge University Press; 1987.

75. Hamilton MJ, Davidson AD, Sibly RM, Brown JH. Universal scaling of production rates across mammalian lineages. Proc R Soc B Biol Sci. 2011;278:560-6.

76. Peters HR. The ecological implications of body size. New York: Cambridge University Press; 1983.

77. Calder WA. Size, function and life history. Cambridge: Harvard University Press; 1984

78. Schmidt-Nielsen K, Knut SN. Scaling: why is animal size so important? Cambridge: Cambridge University Press; 1984.

79. Kaplan RH, Salthe SN. The allometry of reproduction: an empirical view in salamanders. Am Nat. 1979:113:671-89. 
80. Duarte CM, Alearaz M. To produce many small or few large eggs: a sizeindependent reproductive tactic of fish. Oecologia. 1989;80:401-4.

81. Rochet M-J, Cornillon P-A, Sabatier R, Pontier D. Comparative analysis of phylogenetic and fishing effects in life history patterns of teleost fishes. Oikos. 2000;91:255-70.

82. Barneche DR, Robertson DR, White CR, Marshall DJ. Fish reproductiveenergy output increases disproportionately with body size. Science. 2018;360:642-5.

83. Kuramoto M. Correlations of quantitative parameters of fecundity in amphibians. Evolution. 1978;32:287-96.

84. Liedtke HC, Müller H, Hafner J, Nagel P, Loader SP. Interspecific patterns for egg and clutch sizes of African Bufonidae (Amphibia: Anura). Zool Anz. 2014:253:309-15.

85. Rahn H, Paganelli CV, Ar A. Relation of avian egg weight to body weight. Auk. 1975;92:750-65.

86. Blueweiss L, Fox H, Kudzma V, Nakashima D, Peters R, Sams S. Relationships between body size and some life history parameters. Oecologia. 1978;37:257-72.

87. Dunham AE, Miles DB. Patterns of covariation in life history traits of squamate reptiles: the effects of size and phylogeny reconsidered. Am Nat. 1985;126:231-57.

88. Meiri S, Feldman A, Kratochvíl L. Squamate hatchling size and the evolutionary causes of negative offspring size allometry. J Evol Biol. 2015:28:438-46.

89. Schwarz R, Meiri S. The fast-slow life-history continuum in insular lizards: A comparison between species with invariant and variable clutch sizes. J Biogeogr. 2017:44:2808-15.

90. Bakewell AT, Davis KE, Freckleton RP, Isaac NJ, Mayhew PJ. Comparing life histories across taxonomic groups in multiple dimensions: how mammal-like are insects? Am Nat. 2020;195:70-81.

91. Marshall SD, Gittleman JL. Clutch size in spiders: is more better? Funct Ecol. 1994;8:118-24

92. Poulin R, Hamilton WJ. Ecological determinants of body size and clutch size in amphipods: a comparative approach. Funct Ecol. 1995;9:364-70.

93. Arendt JD. Size-fecundity relationships, growth trajectories, and the temperature-size rule for ectotherms. Evolution. 2011;65:43-51.

94. Sauer JR, Slade NA. Size-based demography of vertebrates. Annu Rev Ecol Syst. 1987:18:71-90.

95. James C, Shine R. Life-history strategies of Australian lizards: a comparison between the tropics and the temperate zone. Oecologia. 1988;75:307-16

96. Clobert J, Garland T, Barbault R. The evolution of demographic tactics in lizards: a test of some hypotheses concerning life history evolution. J Evol Biol. 1998;11:329-64.

97. Meiri S, Avila L, Bauer AM, Chapple DG, Das I, Doan TM, et al. The global diversity and distribution of lizard clutch sizes. Glob Ecol Biogeogr. 2020;29:1515-30.

98. Shine $R$, Greer AE. Why are clutch sizes more variable in some species than in others? Evolution. 1991:45:1696-706.

99. Meiri S. What geckos are - an ecological-biogeographic perspective. Isr J Ecol Evol. 2020:66:253-63.

100. Millar JS. Pre-partum reproductive characteristics of eutherian mammals. Evolution. 1981:35:1149-63.

101. Allaine D, Pontier D, Gaillard JM, Lebreton JD, Trouvilliez J, Clobert J. The relationship between fecundity and adult body weight in homeotherms. Oecologia. 1987;73:478-80.

102. Hamilton MJ, Davidson AD, Sibly RM, Brown JH. Universal scaling of production rates across mammalian lineages. Proc R Soc Lond. 2011;278:560-6.

103. Tuomi J. Mammalian reproductive strategies: a generalized relation of litter size to body size. Oecologia. 1980;45:39-44.

104. Jones KE, Bielby J, Cardillo M, Fritz SA, O'Dell J, Orme CDL, et al. PanTHERIA: a species-level database of life history, ecology, and geography of extant and recently extinct mammals. Ecology. 2009;90:2648.

105. Leutenegger W. Evolution of litter size in primates. Am Nat. 1979:114:525-31.

106. Harvey PH, Clutton-Brock TH. Life history variation in Primates. Evolution. 1985;39:559-81.

107. Jetz W, Sekercioglu CH, Bohning-Gaese K. The worldwide variation in avian clutch size across species and space. PLoS Biol. 2008;6:e303.
108. Boyer AG, Cartron JLE, Brown JH. Interspecific pairwise relationships among body size, clutch size and latitude: deconstructing a macroecological triangle in birds. J Biogeogr. 2010;37:47-56.

109. Bohning-Gaese K, Halbe B, Lemoine N, Oberrath R. Factors influencing the clutch size, number of broods and annual fecundity of North American and European land birds. Evol Ecol Res. 2000;2:823-39.

110. Calder WA. The Kiwi and egg design: evolution as a package deal. Bioscience. 1979;29:461-7.

111. Ar A, Yom-Tov Y. The evolution of parental care in birds. Evolution. 1978;32:655-69.

112. Stearns SC. The influence of size and phylogeny on patterns of covariation among life-history traits in the mammals. Oikos. 1983;41:173-87.

113. Yom-Tov Y. The reproductive rates of Australian passerines. Wildl Res. 1987;14:319-30.

114. Jones KE, Purvis A. An optimum body size for mammals? Comparative evidence from bats. Funct Ecol. 1997:11:751-6.

115. Purvis A. The $h$ index: playing the numbers game. Trends Ecol Evol. 2006;21:422.

116. Sibly RM, Brown JH. Mammal reproductive strategies driven by offspring mortality-size relationships. Am Nat. 2009:173:185-99.

117. Sibly RM, Witt CC, Wright NA, Venditti C, Jetz W, Brown JH. Energetics, lifestyle, and reproduction in birds. In: Proceedings of the National Academy of Sciences. USA; 2012. p. 10937-41.

118. Warne RW, Charnov EL. Reproductive allometry and the size-number trade-off for lizards. Am Nat. 2008:172:80-98.

119. Meiri S, Yom-Tov Y. Ontogeny of large birds: migrants do it faster. Condor. 2004;106:540-8.

120. Healy K, Guillerme T, Finlay S, Kane A, Kelly SBA, McClean D, et al. Ecology and mode-of-life explain lifespan variation in birds and mammals. Proc R Soc B. 2014;281:20140298.

121. Stark G, Pincheira-Donoso D, Meiri S. No evidence for the "rate-ofliving"theory across the tetrapod tree of life. Glob Ecol Biogeogr. 2020;29:857-84.

122. Stark G, Tamar K, Itescu Y, Feldman A, Meiri S. Cold and isolated ectotherms: drivers of reptilian longevity. Biol J Linn Soc. 2018;125:730-40

123. de Magalhães JP, Costa J, Church GM. An analysis of the relationship between metabolism, developmental schedules, and longevity using phylogenetic independent contrasts. J Gerontol A Biol Sci Med Sci. 2007:62:149-60.

124. Blackburn DG. Saltationist and punctuated equilibrium models for the evolution of viviparity and placentation. J Theor Biol. 1995;174:199-216.

125. Andrews RM, Karsten KB. Evolutionary innovations of squamate reproductive and developmental biology in the family Chamaeleonidae. Biol J Linn Soc. 2010;100:656-68.

126. Sun Y-Y, Du Y, Yang J, Fu T-B, Lin C-X, Ji X. Is the evolution of viviparity accompanied by a relative increase in maternal abdomen size in lizards? Evol Biol. 2012;39:388-99.

127. Bellini GP, Arzamendia V, Giraudo AR. Is xenodontine snake reproduction shaped by ancestry, more than by ecology? Ecol Evol. 2017;7:263-71.

128. Bellini GP, Arzamendia V, Giraudo AR. Reproductive life history of snakes in temperate regions: what are the differences between oviparous and viviparous species? Amphib-Reptil. 2019:40:291-303.

129. Hughes DF, Blackburn DG. Evolutionary origins of viviparity in Chamaeleonidae. J Zool Syst Evol Res. 2020;58:284-302.

130. Feldman A, Bauer AM, Castro-Herrera F, Chirio L, Das I, Doan TM, et al. The geography of snake reproductive mode: a global analysis of the evolution of snake viviparity. Glob Ecol Biogeogr. 2015;24:1433-42.

131. Myhrvold NP, Baldridge E, Chan B, Sivam D, Freeman DL, Ernest SM. An amniote life-history database to perform comparative analyses with birds, mammals, and reptiles: ecological archives E096-269. Ecology. 2015;96:3109

132. Feldman A. Snake macroecology [PhD Dissertation]. Tel Aviv University; 2015

133. Meiri S. Traits of lizards of the world: Variation around a successful evolutionary design. Glob Ecol Biogeogr. 2018;27:1168-72.

134. Payne RB. Individual laying histories and the clutch size and numbers of eggs of parasitic cuckoos. Condor. 1973;75:414-38.

135. Payne RB. The evolution of clutch size and reproductive rates in parasitic cuckoos. Evolution. 1974:28:169-81. 
136. Schulze-Hagen K, Stokke BG, Birkhead TR. Reproductive biology of the European cuckoo Cuculus canorus: early insights, persistent errors and the acquisition of knowledge. J Ornithol. 2009;150:1-16.

137. Göth A, Evans CS. Egg size predicts motor performance and postnatal weight gain of Australian Brush-turkey (Alectura lathami) hatchlings. Can J Zool. 2004;82:972-9.

138. Meiri S. Length-weight allometries in lizards. J Zool. 2010;281:218-26.

139. Feldman A, Meiri S. Length-mass allometry in snakes. Biol J Linn Soc. 2013:108:161-82.

140. Feldman A, Sabath N, Pyron RA, Mayrose I, Meiri S. Body sizes and diversification rates of lizards, snakes, amphisbaenians and the tuatara. Glob Ecol Biogeogr. 2016;25:187-97.

141. Meiri S. Evolution and ecology of lizard body sizes. Glob Ecol Biogeogr. 2008;17:724-34

142. Uetz P. The reptile database; 2020. http://reptile-database.reptarium.cz. Accessed 1 Oct 2020.

143. Gill F, Donsker D. IOC world bird list; 2020.

144. Burgin CJ, Colella JP, Kahn PL, Upham NS. How many species of mammals are there? J Mammal. 2018;99:1-14.

145. Chamberlain S, Szoecs E, Foster Z, Arendsee Z, Boettiger C, Ram K, et al. Taxize: taxonomic information from around the web. $R$ package version 0.9. 92.2020.

146. Uyeda JC, Zenil-Ferguson R, Pennell MW. Rethinking phylogenetic comparative methods. Syst Biol. 2018;67:1091-109.

147. Labra A, Pienaar J, Hansen TF. Evolution of thermal physiology in Liolaemus lizards: adaptation, phylogenetic inertia, and niche tracking. Am Nat. 2009;174:204-20.

148. Orme D, Freckleton R, Thomas G, Petzoldt T, Fritz S, Isaac N, et al; 2014. http://R-Forge.R-project.org/projects/caper/. Accessed 1 Oct 2020.

149. Upham NS, Esselstyn JA, Jetz W. Inferring the mammal tree: Specieslevel sets of phylogenies for questions in ecology, evolution, and conservation. PLoS Biol. 2019;17:e30000494.

150. Tonini JFR, Beard KH, Ferreira RB, Jetz W, Pyron RA. Fully-sampled phylogenies of squamates reveal evolutionary patterns in threat status. Biol Conserv. 2016:204:23-31.

151. Colston TJ, Kulkarni P, Jetz W, Pyron RA. Phylogenetic and spatial distribution of evolutionary diversification, isolation, and threat in turtles and crocodilians (non-avian archosauromorphs. BMC Evol Biol. 2020;20:81.

152. Cooney CR, Bright JA, Capp EJ, Chira AM, Hughes EC, Moody CJ, et al. Mega-evolutionary dynamics of the adaptive radiation of birds. Nature. 2017;542:344-7.

153. Slavenko A, Tallowin OJ, Itescu Y, Raia P, Meiri S. Late Quaternary reptile extinctions: size matters, insularity dominates. Glob Ecol Biogeogr. 2016;25:1308-20

154. Ives AR. R2s for correlated data: phylogenetic models, LMMs, and GLMMs. Syst Biol. 2019;68:234-51.

155. Rosler H, Wranik W, Kaiser H. Sperm retention in Pristurus flavipunctatus Ruppell, 1835 (Squamata: Sphaerodactylidae), with a brief review of sperm storage in geckos. Herpetol Notes. 2017;10:537-45.

156. Cree A, Cockrem JF, Guillette LJ. Reproductive cycles of male and female tuatara (Sphenodon punctatus) on Stephens island New Zealand. J Zool. 1992;226:199-211.

157. Shoshani J, Eisenberg JF. Elephas maximus. Mamm Species. 1982;182:1-8

158. Howard M. Loxodonta africana (On-line). Animal Diversity Web; 2017. https://animaldiversity.org/accounts/Loxodonta_africana/. Accessed 1 Oct 2020

159. Rahn $\mathrm{H}, \mathrm{Ar}$ A. The avian egg: incubation time and water loss. Condor. 1974;76:147-52

160. Köhler G. Incubation of reptile eggs. Malabar: Krieger Publishing Company; 2005

161. Jameson EW. Patterns of vertebrate biology. Dordrecht: Springer Science \& Business Media; 2012.

162. Ernest SKM, Enquist BJ, Brown JH, Charnov EL, Gillooly JF, Savage VM, et al. Thermodynamic and metabolic effects on the scaling of production and population energy use. Ecol Lett. 2003;6:990-5.
163. Congdon JD, Gibbons JW. Morphological constraint on egg size: a challenge to optimal egg size theory? Proc Natl Acad Sci USA. 1987:84:4145-7.

164. Rollinson N, Brooks RJ. Optimal offspring provisioning when egg size is "constrained": a case study with the painted turtle Chrysemys picta. Oikos. 2008;117:144-51.

165. Janzen FJ, Warner DA. Parent-offspring conflict and selection on egg size in turtles. J Evol Biol. 2009;22:2222-30.

166. Packard GC, Tracy CR, Roth JJ. The physiological ecology of reptilian eggs and embryos, and the evolution of viviparity within the class Reptilia. Biol Rev Camb Philos Soc. 1977;52:71-105.

167. Simkiss K. Calcium metabolism and avian reproduction. Biol Rev. 1961;36:321-67.

168. Simkiss K. The sources of calcium for the ossification of the embryos of the giant leathery turtle. Comp Biochem Physiol. 1962;7:71-9.

169. Stone MD. Effects of season, sex, and age on the calcium physiology and bone dynamics of turtles. Turtles: Oklahoma State University; 2009.

170. Racey PA, Entwistle AC. Life-history and reproductive strategies of bats. In: Crichton EG, Krutzsch PH, editors. Reproductive biology of bats. New York: Academic Press; 2000. p. 363-414.

171. Barclay RM, Harder LD. Life histories of bats: life in the slow lane. Bat Ecol. 2003:209:253.

172. Rensch B. Some problems of geographical variation and species formation. Proc Linn Soc Lond. 1938;150:275-85.

173. Moreau RE. Clutch-size: a comparative study, with special reference to African birds. Ibis. 1944;86:286-347.

174. Lack D. The significance of clutch-size. Ibis. 1947;89:302-52.

175. Ricklefs RE. Geographical variation in clutch size among passerine birds: Ashmole's hypothesis. Auk. 1980;97:38-49.

176. Iverson JB. Correlates of reproductlve output in turtles (order Testudines). Herpetol Monogr. 1992;6:25-42.

177. Grenyer R, Orme CDL, Jackson SF, Thomas GH, Davies RG, Davies TJ, et al. Global distribution and conservation of rare and threatened vertebrates. Nature. 2006;444:93-6.

178. Milewski AV. A comparison of reptile communities in relation to soil fertility in the Mediterranean and adjacent arid parts of Australia and Southern Africa. J Biogeogr. 1981;8:493-503.

179. Morton SR, James CD. The diversity and abundance of lizards in arid Australia: A new hypothesis. Am Nat. 1988;132:237-56.

180. Pianka ER. Desert lizard diversity: additional comments and some data. Am Nat. 1989;134:344-64.

181. Morton SR, Emmott AJ. Lizards of the Australian deserts: Uncovering an extraordinary ecological story. Hist Rec Aust Sci. 2014;25:217-26.

182. Roll U, Feldman A, Novosolov M, Allison A, Bauer AM, Bernard R, et al. The global distribution of tetrapods reveals a need for targeted reptile conservation. Nat Ecol Evol. 2017:1:1677-82.

183. Minias P, Włodarczyk R. Avian developmental rates are constrained by latitude and migratoriness - A global analysis. J Biogeogr. 2020:47:2156-67.

184. Hulbert AJ, Pamplona R, Buffenstein R, Buttemer WA. Life and death: metabolic rate, membrane composition, and life span of animals. Physiol Rev. 2007;87:1175-213.

185. Capdevila P, Beger M, Blomberg SP, Hereu B, Linares C, Salquero-Gomez R. Longevity, body dimension and reproductive mode drive differences in aquatic versus terrestrial life history strategies. Funct Ecol. 2020;34:1613-25

\section{Publisher's Note}

Springer Nature remains neutral with regard to jurisdictional claims in published maps and institutional affiliations. 